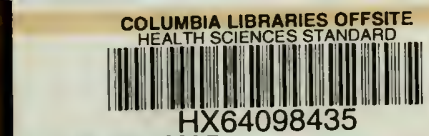

\title{
RECAP
}

An Eskimo Brain

BY

ALEŠ HRDLIČKA, M.D.

NEW YORK

THE KNICKERBOCKER PRESS

NEW YORK

I9OI 


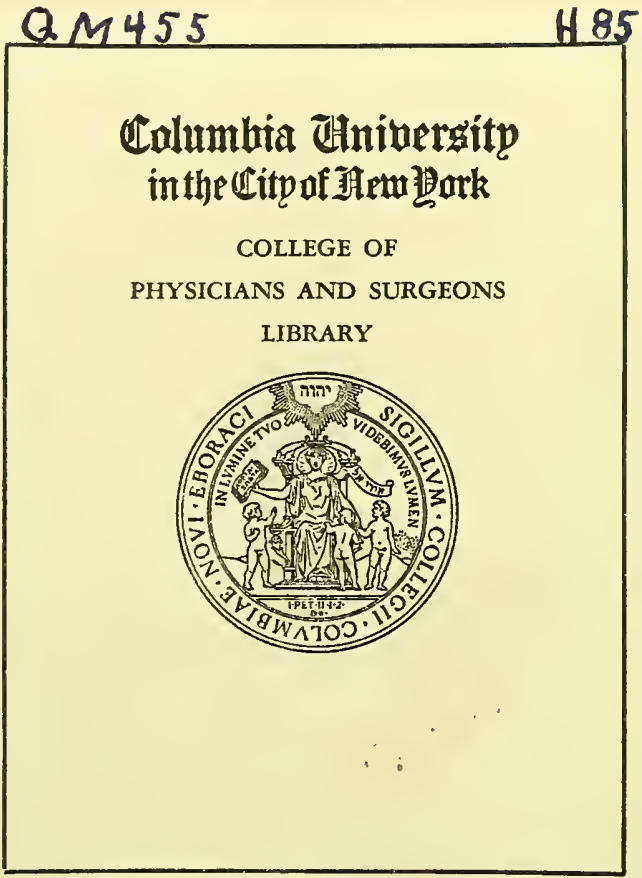


Digitized by the Internet Archive in 2010 with funding from Columbia University Libraries 



\section{An Eskimo Brain}

BY

ALEŠ HRDLIČKA, MI.D.

NEW YORK

THE KNICKERBOCKER PRESS

NEW YORK

1901 




\section{An Eskimo Brain}

BY

ALEŠ HRDLIČKA, M.D.

NEW YORK

THE KNICKERBOCKER PRESS

NEW YORK

I 901 


$$
\begin{aligned}
& \text { QM455 } \\
& H_{85}
\end{aligned}
$$

4013778 

PLATE I

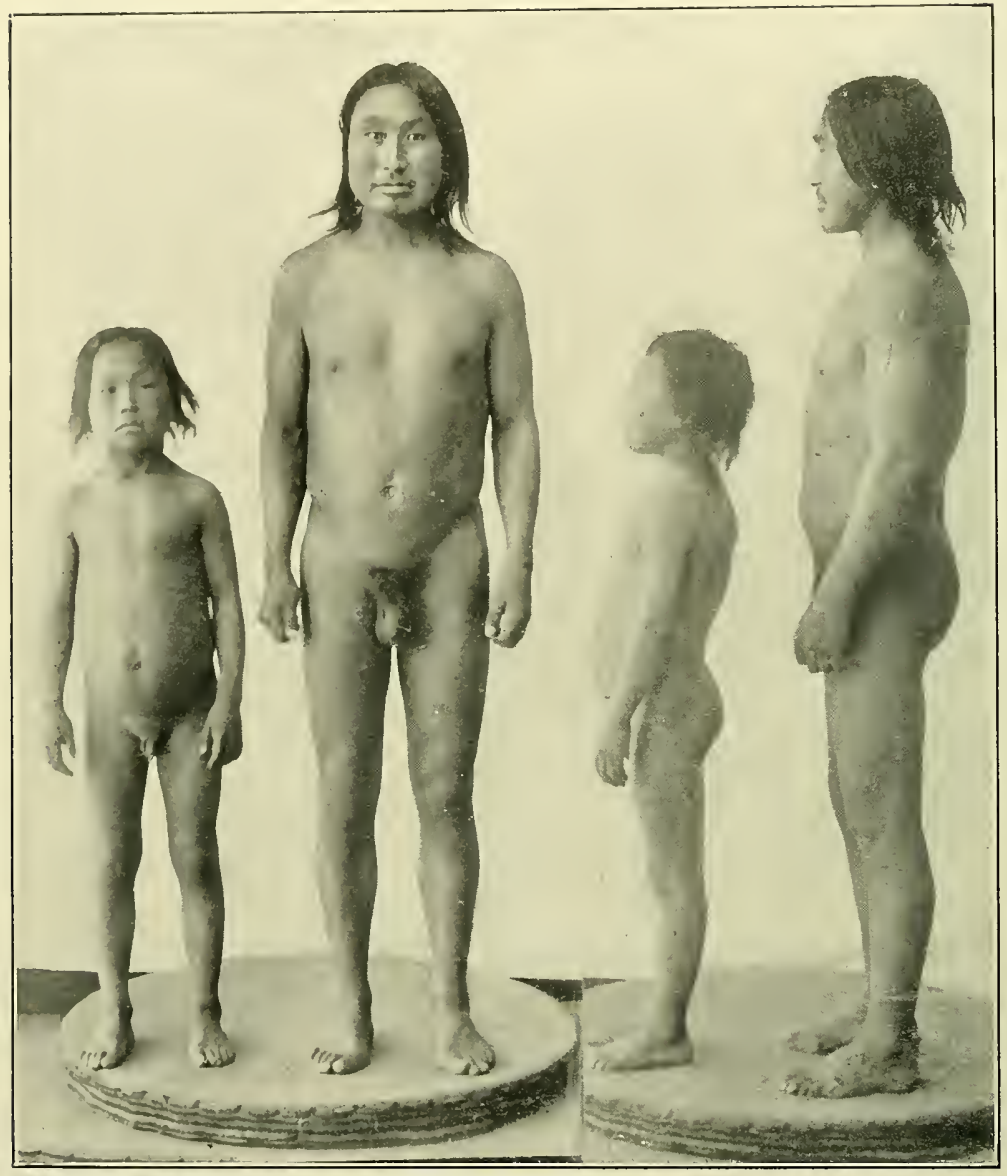

KISHU AND MENEE (PHOTOGRAPHED ON THEIR ADMISSION TO BELLEVUE HOSPITAL) 


\section{AN ESKIMO BRAIN}

\section{BY ALEŠ HRDLIČKA}

The brain in question ' is that of Kishu (or Kissuk), an adult male Eskimo of about forty-five years of age, who died of acute general tuberculosis. ${ }^{2}$ Kishu was a chief of his tribe; he measured I.64 m. in height, weighed about I70 lbs., was muscular, and in every respect normally developed. He died at Bellevue Hospital within less than five months after the inception of his disease. Plate XIII shows him (together with his son) as he appeared on admission to the hospital.

The autopsy was performed in my presence by Dr Harlow Brooks. I am indebted to Dr Brooks for notes concerning the general condition of the brain and its membranes, and to the authorities of Bellevue hospital and the American Museum of Natural History for the privilege of examining the specimen. Before the skull was opened, I obtained the following measurements of the head:

Diam. antero-post. $\max . \ldots \ldots \ldots \ldots \ldots$. $9.8 \mathrm{~cm}$.

Diam. lateral $\max . \ldots \ldots \ldots \ldots \ldots \ldots \ldots .15 \mathrm{~cm}$.

${ }^{1}$ The specimen was examined in 1896 and reëxamined in Igor. A preliminary report on it was published by the author in the Proceedings of the Amer. MedicoPsychological Assoc., I899, and a full report in the AMERICAN ANTHRopologist, N. S., 3, I9oI.

${ }^{2}$ Kishu was one of the six Eskimo who were brought to New York in 1896 by Lieutenant Peary, from the neighborhood of Smith sound. Of these six Eskimo, four, including Kishu, have since succumbed to acute tuberculosis; one was sent back to Smith sound, and a boy of about twelve years survives, after having recovered from incipient pulmonary tuberculosis, in the care of Mr Vallace, the former Superintendent of the American Museum of Natural History. The brains of the three other Eskimo who died, as well as an additional specimen, - the brain of an Eskimngirl from Alaska, -will be reported upon in detail by Mr Edward A. Spitzka, of Columbia College. Some measurements and observations which I have made of these brains will be included, for comparison, in this paper. 
(Cephalic index 76.26.)

Height (from line joining the aud. meati to bregma) about.............. $14.2 \mathrm{~cm}$.

Circumference maximum of the head .... $56.8 \mathrm{~cm}$. Diam. biauricular (between the depressions over the roots of zygomæ, in front of

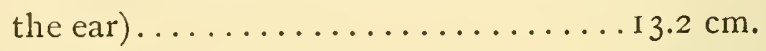

Diam. frontal minimum............ $10.4 \mathrm{~cm}$.

Diam. bigonial................. I I. cm.

Diam. bizygomatic $\max . \ldots \ldots \ldots \ldots \ldots 14.5 \mathrm{~cm}$.

Height of face : chin to nasion......... $12.3 \mathrm{~cm}$.

chin to interciliary line.... I $4.3 \mathrm{~cm}$.

chin to insertion of hair....20.0 cm.

These measurements agree in the main with those which I made of the other Eskimo from the same locality, thus showing that Kishu was not racially exceptional.

The scalp was found to be less than the average in thickness; this was undoubtedly due to advanced general emaciation. The skull was entirely symmetrical; the sutures mostly still pervious; skull-cap thin. No adhesion of the dura; the soft membranes normal. Several masses of Pacchionian granulations over the longitudinal sinus. No signs of tuberculosis, ${ }^{1}$ nor any other pathological lesion, within the cranial cavity. Very small quantity of fluid. There was a pronounced pigmentation of the pia and arachnoid from the pons to over and below the calamus scriptorius.

Weight of brain, denuded of dura mater, after a few minutes' exposure for drain, 1503 grammes. ${ }^{2}$ The specimen was laid in 20 parts $5 \%$ formaline and 80 parts $95 \%$ alcohol.

\footnotetext{
${ }^{1}$ The brain and the heart were about the only organs in which no tubercular lesions were found.

${ }^{2}$ Mean weight of white male brain in 154 men of mean height of $1.680 \mathrm{~m}$, equals 1361.5 grams (Broca); mean weight of white male brain in 168 men of mean height of $1.679 \mathrm{~m}$. equals 1357.5 grams (Manouvrier).
} 


\section{Examination of the Brain}

(Three weeks after death)

$$
\text { Weight }
$$

The brain and its principal parts, denuded of the membranes, weigh, after 15 minutes' drainage, as follows:

Whole encephalon.............. $1325.0 \mathrm{gr}$.

(Loss in three weeks through solution and

through loss of membranes....... I $78.0 \mathrm{gr}$.)

Cerebrum....... II 55.0 gr. or $87.17 \%$ of the total.

Right hemisphere............ 5i7.0 gr.

Left hemisphere............. $578.0 \mathrm{gr}$.

Cerebellum .....142.0 gr. or $10.72 \%$ of the total.

Pons and bulb......2\$.० gr. or 2.1\% of the total.

The proportions of the cerebrum and cerebellum to the whole brain are very nearly like those of whites, ${ }^{1}$ but the relative weight of the pons and bulb is slightly greater.

\section{GENERAL OBSERVA'TIONS}

\section{Cerebrum}

The hemispheres in general are very well developed. The gyration is pronounced and rather more complex than that found on the brains of average whites. The principal sulci are deep. The thickness of the gray matter shows no appreciable difference from that observed in the brains of whites. The gyration of the left hemisphere is perceptibly more complex, particularly in the frontal lobes, than that of the right. A striking feature is the predominance on both hemispheres, but more especially on the right, of vertical gyration.

\footnotetext{
${ }^{1}$ In the white brain, the proportionate weight of the cerebellum, medulla, and pons together is to that of the while brain in the adult as 33 to 87 (Huschke). The cerebellum is 10.7 of the total encephalon (.1/eynert). According to Broca, the relative weights to that of the whole encephaion are : cerebrum, $87.3 \%$; cerebellum, 10.6\%; pons and bulb, 1.91\%. As to the hemisphere, in 264 men Broca found the right to be the heavier in 138 cases, the left in rus cases; the weight was even in 21 cases.
} 
The hemispheres show certain gross and many small asymmetries. The principal of the gross asymmetries are the differences in the limbic, temporo-sphenoidal, and occipital lobes. All these, as well as the minor peculiarities of the brain, will be described later.

Norma Superior.-Viewed from above, the cerebrum is distinctly hexagonal in its outline. The longest sides of the hexagon are the antero-lateral lines, upon which follow, in the order named, the anterior, the postero-lateral, and the posterior lines. The outline of the frontal lobes is quite angular.

The Norma Lateralis, or the outline of the cerebrum when looked at from the side, is obliquely quadrilateral. The anteroinferior line (base of the frontal with the antero-inferior boundary of the temporal lobes), and the postero-inferior boundary (base of temporal and occipital lobes), are nearly straight. The two superior lines, moderately convex, meet over the precuneus.

The right temporal lobe is perceptibly higher than the left.

There are a few specially prominent points on the external surface of each hemisphere: on the left such points are the supramarginal and the second temporal gyri; on the right, the supramarginal (somewhat less than on left), second temporal, and ascending parietal convolutions.

Norma Ventralis, or the outline of the base of the hemispheres, is oval, almost square anteriorly and tapering posteriorly. The basal surface of the frontal lobes slopes toward the middle and there is a marked elevation on each frontal lobe along the median fissure. These elevations are somewhat larger than those found ordinarily in the brains of whites. The olfactory nerves run along their middle. Each of the elevations comprises approximately two-sevenths of the base of each frontal lobe, and they, together with the sloping of the rest of the basal surfaces, impart to the inferior portion of the approximated frontal lobes a boat-keel-like appearance.

Norma Anterior.-The outline of the anterior lobes forms 
superiorly and laterally a regular arch, while inferiorly it consists of two shallow arches (concavities of the inferior surface of the frontal lobes), which meet over the median eminence. The outer terminal points of the arches are, as usual, situated higher than the inner ones.

The anterior surface of the frontal lobes is almost vertical.

\section{Principal Measurements of the Cerebrum ${ }^{1}$}

Length maximum of left hemisphere........ $18.0 \mathrm{~cm}$.

Length maximum of right hemisphere...... $17.9 \mathrm{~cm}$.

Width maximum of cerebrum.......... $13.6 \mathrm{~cm}^{2}$

As to the parts situated at the base of the cerebrum, nothing unusual was found. The anterior perforated spaces are not appreciably larger than in whites. The optic commissure is well formed; the optic nerves are strong. Hypophysis of ordinary size and appearance. Crura cerebri, cut at the niveau of the mesial border of the hippocampal gyri, are exactly equal in size. Their cross-section measures on each side $2.8 \mathrm{~cm}$. in greatest length and $1.7 \mathrm{~cm}$. in greatest width.

There were no marked anomalies in the cerebral circulation. The ventricles were not opened.

\section{External Conformation of the Hemispheres}

PRINCIPAL SINUOSITIES. FISSURE OF SYLVIUS

The horizontal and ascending, or, more properly in this case, the anterior and posterior, branches of the presylvian begin separately, from the superior limiting sulcus of the insula on the right, and from a common fovea, connecting with that sulcus, on the left side. ${ }^{3} \quad$ The anterior branch is in line with, and appears like a continuation of, the anterior limiting sulcus of the insula.

1 For additional and comparative measurements, see the end of the paper.

${ }^{2}$ By an oversight this measure was given in the preliminary report as $14.2 \mathrm{~cm}$., which was incorrect.

${ }^{3}$ This, according to Cunningham, is also frequently the case in whites. In 80 hemispheres examined by that author, two separate limbs of the presylvian were found 15 times $(32.6 \%)$ on the right and 15 times $(44.1 \%)$ on the left side. 
Length of the anterior branch, $1,2.8 \mathrm{~cm} ., \mathrm{r} ., 2.6 \mathrm{~cm}$.

Length of the posterior branch, $1 ., 1.2 \mathrm{~cm}$., r., $2.0 \mathrm{~cm}$.

On the left the posterior branch is very short, and on both sides the anterior branch is the longer (the reverse of that generally found in white people).

The anterior branch connects on the right, over a submerged but not deep gyrus, with a descending branch from the inferior frontal sulcus.

The several important opercula situated along the lower border of the hemispheres in the neighborhood of these two anterior branches of the Sylvian, differ somewhat in size and form. (See the description of the inferior frontal gyrus.)

The stem or main limb of the Sylvian runs in a nearly straight line; it measures, from the anterior branch of the presylvian to the bifurcation, $6.5 \mathrm{~cm}$. on the left and $5.2 \mathrm{~cm}$. on the right hemisphere. ${ }^{1}$

The depth of the Sylvian fissure is considerable throughout. It measures :

Left

At the origin $(\mathrm{x})$ of the anterior branches ...... $3.0 \mathrm{~cm}$.

In middle between $\mathrm{x}$ and the precentral sulcus... $2.9 \mathrm{~cm}$. Opposite the precentral sulcus ............. $2.8 \mathrm{~cm}$.
Right

$3.1 \mathrm{~cm}$.

$2.6 \mathrm{~cm}$.

$2.7 \mathrm{~cm}$.

The anterior branch of the presylvian measures at middle, left, $2.4 \mathrm{~cm}$.; right, $2.2 \mathrm{~cm}$. Of the terminal branches of the Sylvian, the superior measures, left, $2.6 \mathrm{~cm}$.; right, $2.2 \mathrm{~cm}$. The inferior measures, left, $1.8 \mathrm{~cm}$. ; right, about $0.8 \mathrm{~cm}$. in depth.

The above figures show that, except at its beginning, the left Sylvian is the deeper at all points of measurement.

The main limb of the Sylvian presents the following points of interest on the two sides of the brain :

On the left, $0.5 \mathrm{~cm}$. behind the posterior presylvian, there begins within the Sylvian, over a deep annectent loop, by means

1 The left fissure is longer than the right one in the whites; and the disproportion "is evident at all points of growth" (Cunningham, Contr. to the Surf. Anat. of the Cerebr. Hemispheres, I892, p. I27; also Eberstaller). 
of the diagonal sulcus, a pronounced, long, composite, vertical furrow, which runs nearly parallel with the central fissure and the precentral sulci, and terminates above not far from the superior border of the hemisphere. The sulcus shows a number of medium deep and deep annectent fascicles.

On the right a similar furrow begins from the Sylvian, over a submerged loop, $0.6 \mathrm{~cm}$. posteriorly to the hinder branch of the presylvian, and ascends in a quite straight line to within a few millimeters of the superior frontal sulcus. This furrow, in average as well as at maximum, is deeper than that on the left (maximum depth on the right, $1.7 \mathrm{~cm}$.).

A little over $1.0 \mathrm{~cm}$. posteriorly to the last mentioned furrow there begin from the Sylvian, on both sides, over a loop situated very deeply on the right and at medium depth on the left, the central fissures.

The base of the ascending frontal gyrus shows on each side a small trans-precentral, the base of the ascending parietal convolution a similar trans-postcentral sulcus. These sulci on the right side are entirely hidden in the Sylvian, but on the left side both reach to and slightly beyond the inferior border of the convolutions.

Finally, $0.5 \mathrm{~cm}$. anterior to the bifurcation on the right and almost at it on the left, the Sylvian connects on each side, over a submerged but quite superficial gyrus, with the united postcentral sulcus.

The inferior lip of the Sylvian shows on the left the extremities of four, on the right of three, transtemporal depressions. One of these furrows on the left and one on the right effect a shallow communication with the superior temporal sulcus.

Of the terminal branches of the Sylvian the superior is $2.4 \mathrm{~cm}$. in length on the left, and $2.6 \mathrm{~cm}$. on the right side; they both end, as usual, in the supramarginal gyrus. The inferior ramus on the left runs $3.0 \mathrm{~cm}$. horizontally and bifurcates; one of its branches, $2.5 \mathrm{~cm}$. long, passes upward into the angular gyrus, while the other, $1.0 \mathrm{~cm}$. long, descends backward. On the right 
the inferior terminal branch runs $1.5 \mathrm{~cm}$. backward and downward and joins, over a deep gyrus, the first temporal sulcus.

The superior terminal branch on the left makes two connections: one, shallow, posteriorly, with a sulcus running downward and forward from the interparietal, and one, deeper, anteriorly, with a horizontal furrow running backward from the lower part of the postcentral sulcus. The inferior branch on the left connects, not far from the bifurcation, over a submerged annectent gyrus, with the posterior portion of the first temporal sulcus.

On the right side the superior terminal branch of the Sylvian fissure is better developed than the inferior, and is deeper than the latter. It ascends for $2.0 \mathrm{~cm}$. into the supramarginal gyrus, running parallel to the central fissure, and ends in a short $T$. The lower terminal branch descends for $1.3 \mathrm{~cm}$., over two medium deep anastomotic fascicles, and joins the ascending ramus of the first temporal sulcus.

Annectent Gyri.-On the left a strong column, at medium depth, between parietal and temporal lobes, at the beginning of the lower terminal branch of the Sylvian. On the right a similar but more superficial column, at the beginning of the inferior branch, and another more posteriorly in the same.

CENTRAL FISSURE

Length (in a straight line, with

Left

Right

sliding compass)......9.0 cm. (50\% of the total

length of the

hemisphere)

Depth, maximum........2.3 $\mathrm{cm}$.

$2.5 \mathrm{~cm}$.

The fissure begins on both sides within the Sylvian, probably by means of the subcentral sulci of Eberstaller. ${ }^{2}$ The origin

${ }^{1}$ According to Schäfer (Quain's Anat., Ioth ed., III, I, p. I43), " the length of the fissure in whites is about $2 / 5$ ( or $40 \%$ ) of the whole length of the hemisphere. It is relatively longer and more curved in the anthropoid apes than in man." (See additional measurements.)

${ }^{2}$ Cunningham (op. cit., 63) found a connection of the central and Sylvian in I9\% of hemispheres (of whites); Benedict (Anat. Studien an Verbrecher-Gehirnen, 
PLATE \|

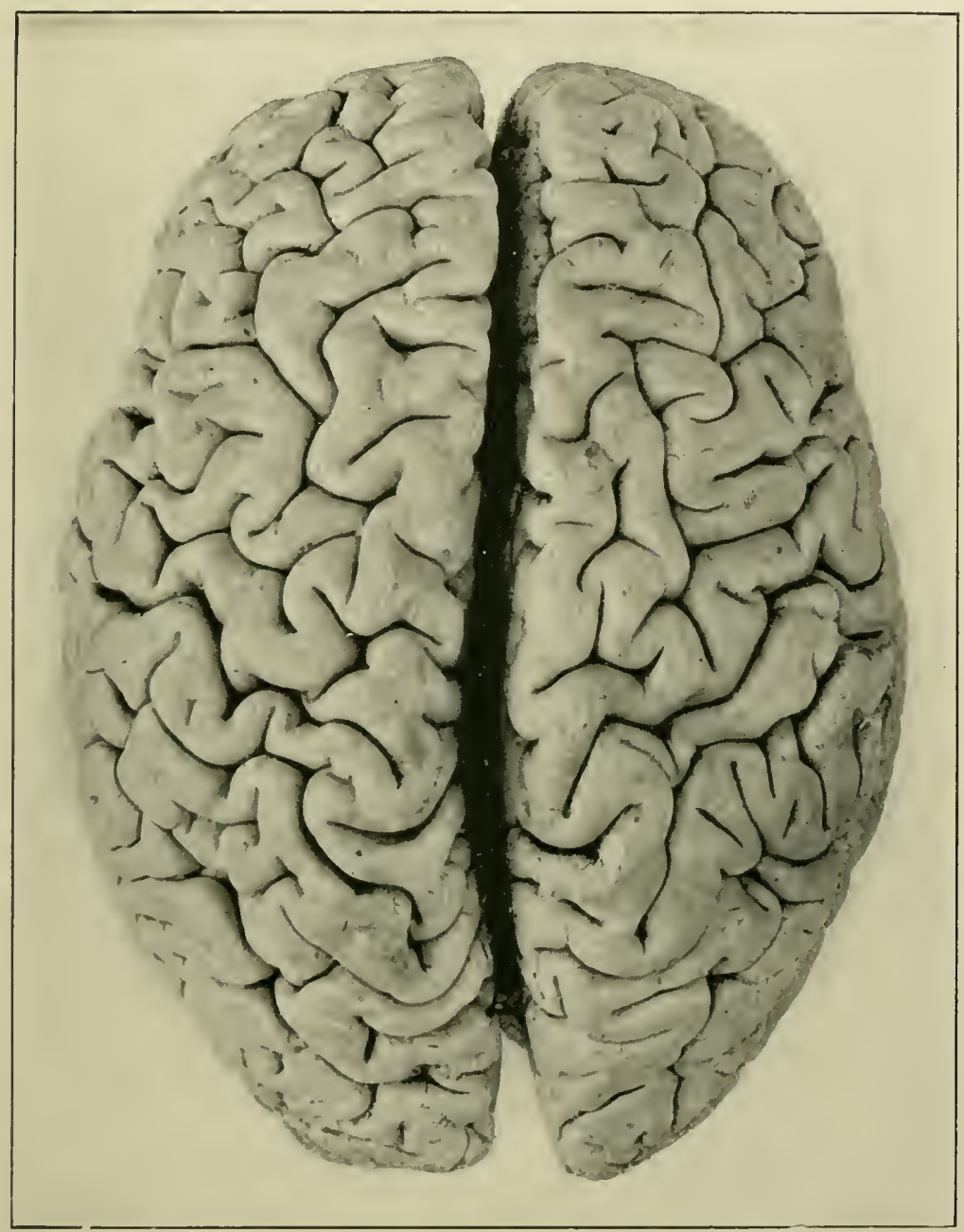

KISHU'S CEREBRUM (DORSAL ASPECT) 

of the central fissure is situated $0.6 \mathrm{~cm}$. below the borders of the Sylvian on the left, and $1.5 \mathrm{~cm}$. on the right It nearly connects on the right with the superior limiting sulcus of the insula. A short distance above the Sylvian border, the left central fissure shows a submerged, but not very deep, annectent gyrus; on the right there are two such fascicles in a similar location.

The form of the central fissure is quite tortuous, especially on the right. The left fissure, neglecting minor bends, is, from above downward and with reference to the frontal lobe, convex, concave, convex, concave, much convex, and nearly straight; that on the right, convex, concave, convex, concave, convex.

Each of the fissures sends a number of incisures into the adjacent convolutions. On the right, $3.3 \mathrm{~cm}$. above the Sylvian, the central fissure connects, over a quite superficial annectent gyrus, with the postcentral sulcus.'

The two fissures show no submerged interruption.

The superior ends of the central fissures are situated almost opposite; distance from the same to the superior border, left, 0.5 $\mathrm{cm}$. ; right, $0.5 \mathrm{~cm}^{2}$

Additional measures:

(I) Origin of central fissure (on the lip of the Sylvian) to frontal pole ${ }^{3} \ldots \ldots \ldots \ldots \ldots \ldots .3 \mathrm{~cm} . \quad 6.5 \mathrm{~cm}$.

(2) Superior extremity of central fissure to frontal pole.................. $10.9 \mathrm{~cm} . \quad 10.8 \mathrm{~cm}$.

Wien, $1872, p . g 6)$ found a complete connection in 18 and an incomplete one in 6 of 38 hemispheres examined. Giacomini (Varietà d. circonvoluzioni cerebrali dell' uomo, Torino, 1882 , cited by Cunningham) found such a connection only in 21 among 336 hemispheres. Retzius (Das Menschengehirn, 1896, I, p. 100) found the connection in $23 \%$ of the hemispheres of Swedes.

${ }^{1}$ Retzius observed, on the brains of whites, anastomosis of the Rolandic fissure with the inferior postcentral sulcus in $9 \%$, with the superior in $3 \%$ of the cases.

${ }^{2}$ Cunningham (op. cit., p. 162), in 52 hemispheres of white children and adults, found the following conditions in this respect: "(a) In $60 \%$ the upper end of the fissure cut the upper border of the hemisphere and appeared on the inner surface ; (b) in $21 \%$ it just reached the upper border; and (c) in $19 \%$ it fell short of the upper border."

This and the following measures are the horizontal distances between vertical planes at the points mentioned. 


\section{Left}

Right

(3) Origin of central fissure to occipital pole.... $10.7 \mathrm{~cm}$.

(4) Superior extremity of central fissure to occipital pole................ 7.1 cm.

Reduced to per cent. of the total antero-posterior diameters of the hemispheres, these distances are:

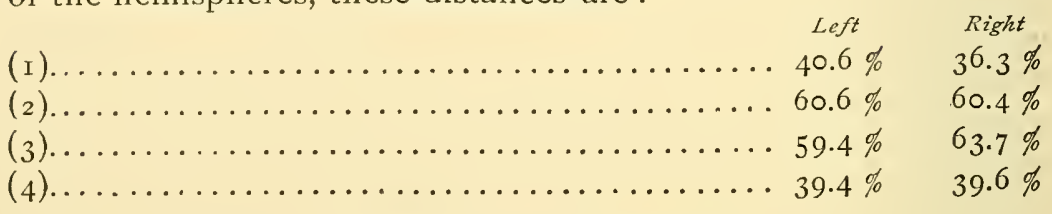

PARIETO-OCCIPITAL FISSURE

The fissure appears on both sides like a direct and equally deep continuation of the calcarine stem. It runs on each side, in nearly a straight line, upward and slightly backward to, and on the left $2.1 \mathrm{~cm}$., on the right $1.5 \mathrm{~cm}$., over, the superior border of the hemisphere. The extremity forms on each side a small $\mathrm{T}$, which is surrounded by a pronounced paroccipital gyrus.

The average depth of the fissure is $2.3 \mathrm{~cm}$. on the left and 2.3 $\mathrm{cm}$. on the right side; its length, from its junction with the calcarine stem to the superior border is on the left $4.0 \mathrm{~cm}$., on the right $4.2 \mathrm{~cm}$.

The fissure on the left connects over a submerged but quite superficial gyrus with the sub-precuneal sulcus, while that on the right shows a slightly deeper connection with a sulcus from the cuneus.

There are only a few very deep annectent bundles within each fissure.

\section{CALCARINE STEM AND SULCUS}

The stem is simple, its course on each side slightly wavy. Its length is $2.6 \mathrm{~cm}$. on the left, $3.3 \mathrm{~cm}$. on the right; its average depth on both sides about $1.5 \mathrm{~cm}$. ; at its junction with the parieto-occipital it equals the latter in depth.

Both calcarine sulci communicate with the stem over a submerged but not very deep gyrus. The left sulcus is nearly 
straight; the right one describes anteriorly a moderate curve. The sulcus on the left is free from connections and gives off but two small incisures; that on the right connects superficially with a cuneal sulcus and sends from its curve a deep branch, $1.0 \mathrm{~cm}$. long, downward to the basi-mesial border.

The calcarine sulcus extends on both sides to the dorsal surface of the occipital lobe, and terminates in a small bifurcation. The most distal point is on the left $1.55 \mathrm{~cm}$., on the right $\mathrm{I} .3 \mathrm{~cm}$, in a straight line beyond the border of the hemisphere.

The length of the calcarine sulcus from its junction with the stem to the border of the occipital lobe is $4.6 \mathrm{~cm}$. on the left, 4.8 $\mathrm{cm}$. on the right side. It is on both sides much shallower than the stem.

There are a number of connecting fasciculi within the two calcarine stems and sulci. On the left there is a deep bundle in about the middle of the stem and reaching from the base of the stem to the point of the cuneus; there are also two bundles at medium depth behind the junction of the stem and the sulcus and passing from the gyrus lingualis to the cuneus; and there is another fascicle of medium depth in the sulcus, about $2 \mathrm{~cm}$. from the occipital border. On the right side we find similar annectent gyri in similar locations, but the bundle in the stem passes downward to the bottom and does not visibly reach the cuneus.

\section{COLLATERAL FISSURE}

This furrow is of considerable extent, particularly on the right. Its total length, in a straight line, is $8.15 \mathrm{~cm}$. on the left, and $\mathrm{I} 1.3 \mathrm{~cm}$. on the right.

The anterior termination of the fissure is on both sides free and simple; it is distant from the pole of the temporal lobe on the left $5.7 \mathrm{~cm}$., on the right $2.9 \mathrm{~cm}$.

On both sides, nearly in the line of continuation of the collateral fissure and incising the antero-mesial border of the temporal lobe, is found a well-developed fissura rhinica. This furrow is 
particularly marked on the left side where the collateral is shorter.

Posteriorly, the left collateral fissure terminates in a line about $3 \mathrm{~mm}$. from the border of the hemisphere, while on the right it reaches the border. Both of the fissures connect, each by a shallow sulcus, with the third temporal.

Each collateral gives off several incisures. In the posterior half of both fissures are found, at medium depth, annectent bundles which pass between the fusiform and lingual lobules.

\section{CALLOSO-MARGINAL FISSURE}

The gyration on the mesial surface of this brain presents several very interesting modifications. The calloso-marginal is duplicated on the left and almost triplicated on the right side. The main fissure is on both sides throughout continuous and connects freely and deeply with the paracentral. It is on both sides doubled by a pronounced mesial frontal sulcus. This is deep and continuous on the left, more shallow and interrupted by an isthmus on the right. In addition the right callosal gyrus is traversed along its entire superior extent by a shallow, interrupted sulcus, which runs parallel with the calloso-marginal fissure and separates the surface of the callosal into two nearly equal superior and inferior portions.

The left calloso marginal begins in a simple way below the genu of the callosum; the right proceeds from a subrostral sulcus which curves about a lobule on the posterior extremity of the mesial portion of the frontal lobe.

During its course, each of the calloso-marginal fissures gives off a few small branches or incisures. On the left, as well as on the right, four such small branches indent the superimposed part of the superior frontal gyrus.

There is on both sides a well-developed rostral, and on the right also a transverse subrostral sulcus; there is also a fair representation on each side of the postlimbic sulcus. 


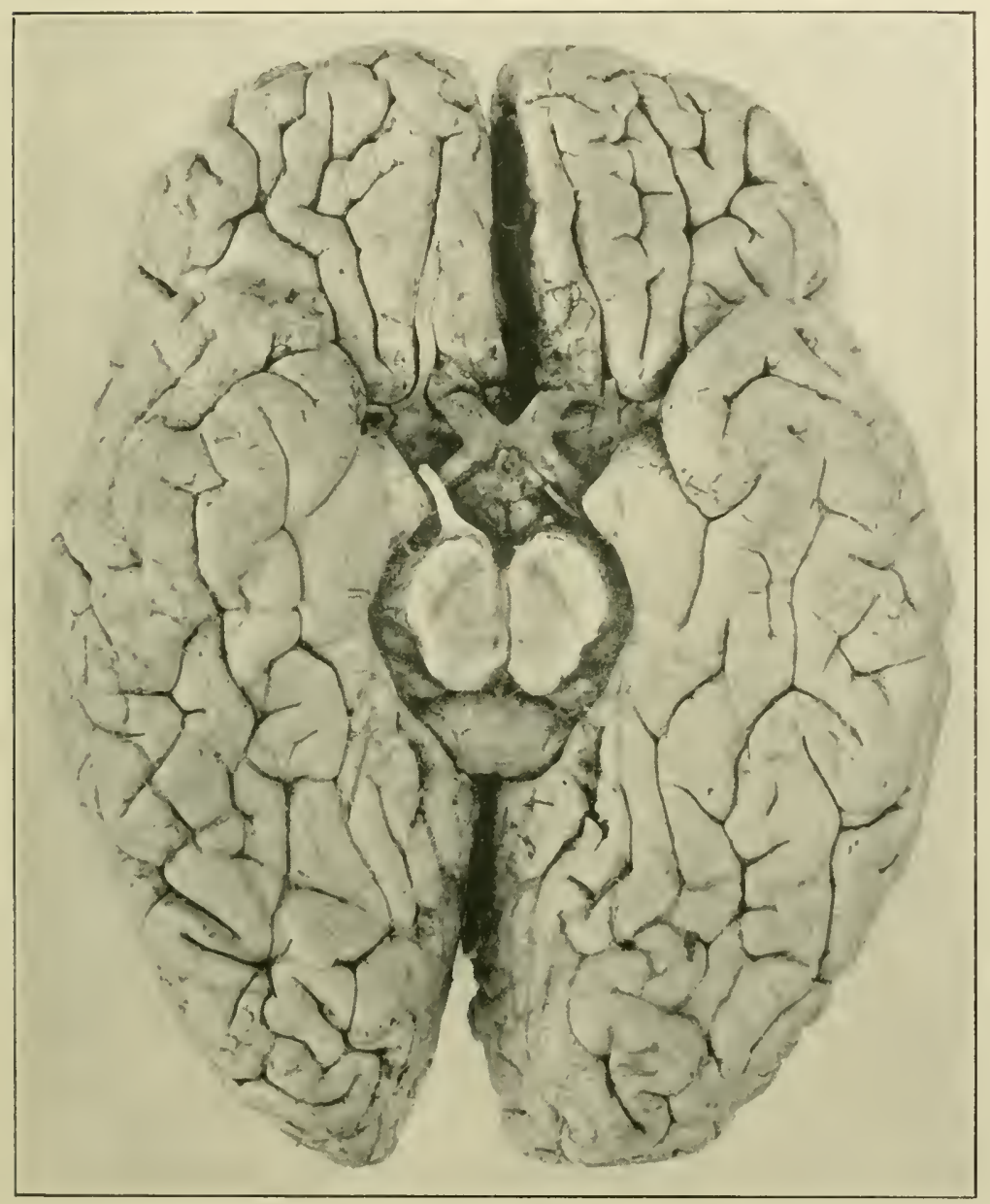

KISHU'S CEREBRUM (BASAL ASPECT) 

The paracentral sulci are well curved and both end on the dorsal surface of the hemisphere : the left in a line, $1.5 \mathrm{~cm}$. from the median border and $0.7 \mathrm{~cm}$. behind the superior extremity of the central fissure; the right in a $\mathrm{T}$, with the posterior branch much shorter than the anterior, $1.6 \mathrm{~cm}$. from the median border of the hemisphere and $0.5 \mathrm{~cm}$. behind the terminus of the central fissure.

The average depth of the calloso-marginal is $1.0 \mathrm{~cm}$. on the left, $\mathrm{I} .3 \mathrm{~cm}$. on the right; that of the paracentral $1.5 \mathrm{~cm}$. on the left and $\mathrm{r} .8 \mathrm{~cm}$. on the right side.

Annectent Gyri.-There are in the calloso-marginal five or six deep bundles on the left and seven or eight such bundles on the right, passing between the callosal gyrus, the superior frontal convolution, and the paracentral lobule.

MINOR FISSURES OR SULCI

Frontal Lobe.-The superior frontal sulcus on the left is a continuous furrow, which runs, in a tortuous way, from the anterior portion of the orbital surface to within a few millimeters of the superior precentral sulcus. On the right a similar but somewhat less tortuous furrow extends from the orbital border of the frontal lobe to the superior precentral sulcus, connecting with the same.

Each of the sulci sends off a number of transverse branches and incisures. That on the left communicates with the medial frontal sulcus of Eberstaller and with the vertical furrow anterior to the precentral sulci; that on the right connects with the medial frontal and the superior precentral sulcus.

The depth of each of the superior frontal sulci averages about I.5 $\mathrm{cm}$., the maximum depth measured being $2.8 \mathrm{~cm}$. (on the left).

Mesially from the superior frontal sulci we find on each side of the brain, but particularly on the left, small segments of Cunningham's mesial sulcus. 
The medial frontal sulci of Eberstaller are only fairly well represented.

The inferior frontal sulcus can be isolated with more facility on the left than on the right hemisphere; it does not connect on either side with the inferior precentral sulcus.

The left inferior frontal sulcus is in two portions; it begins posteriorly $3 \mathrm{~mm}$. in front of the middle of the inferior precentral, intersects the anomalous vertical furrow, and terminates about $2 \mathrm{~cm}$. in front of this furrow in a shallow Y. A few millimeters inferiorly and posteriorly to the lower terminal branch of this $\mathrm{Y}$ begins the second portion of the sulcus. This portion consists mainly of the sulcus radiatus, and sends six branches into the adjacent convolutions.

On the right side, that part of the vertical furrow which corresponds to the diagonal sulcus connects, $1.9 \mathrm{~cm}$. above the Sylvian, with a short but deep T branch, $1.0 \mathrm{~cm}$. long, which runs directly forward and probably represents the posterior extremity of the inferior frontal sulcus. The anterior portion of the same consists of the sulcus radiatus, possibly joined with the frontomarginal sulcus. This portion, as on the left, shows six branches. One of these connects inferiorly with the anterior branch of the presylvian; another ascends to within a short distance of the median frontal sulcus.

A small independent depression indents on each side the surface of the pars triangularis of the inferior frontal gyrus.

All the frontal sulci show numerous submerged annectent gyri.

The anomalous vertical furrow which runs on each side anterior to and nearly parallel with the precentral sulci, has been referred to in the description of the Sylvian.

The precentral sulcus consists on each side of two independent, radiating segments of considerable depth. On the left these segments are isolated; on the right the superior connects, over a deep annectent bundle, with the first frontal sulcus, while the 
inferior joins and probably forms the superior part of the anomalous vertical furrow.

Above the superior precentral there is on each side an independent, triradiate sulcus extending to the upper border of the hemisphere and bounding laterally the ascending frontal convolution; it looks like a third part of the precentral.

Orbital Surface.--The Sulcus Olfactorius presents a typical conformation. It is a long depression, running from $1.0 \mathrm{~cm}$. at base to $0.5 \mathrm{~cm}$. at terminus laterally to the median fissure, quite deep, terminating on the left side in a free line and on the right side in a small $\mathrm{Y}$. Slightly anteriorly to the end a small transverse sulcus crosses the border of the hemisphere on the left, and a small semicircular sulcus indents the border on the right side. The parts of the first frontal gyrus traversed by the olfactory sulcus are, as previously stated, quite prominent.

Besides the olfactory, each of the orbital parts shows two other antero-posterior sulci. One of these, the outer, is apparently the orbital sulcus. Its form on the left is that of a $\mathrm{Y}$, or of a $\mathrm{K}$ with the lower branch interrupted, while on the right side it forms a somewhat crooked X.

Both of these figures are situated somewhat more externally than is usual, and between them and the olfactory furrows we find on each side a distinct separate sulcus. On the left this sulcus consists of two branches and indents the first frontal convolution. The anterior branch communicates with the main ramus of the orbital sulcus. On the right side the sulcus begins near the root of the olfactory nerve and then passes forward, bounding the first frontal gyrus.

The transverse orbital sulci present nothing extraordinary.

Parietal Lobe.-The postcentral sulcus shows neither on the left nor on the right any superficial interruption.' It connects on

${ }^{1}$ According to Cunningham, in the brains of adult Irishmen the postcentral sulcus was found complete and separaled from the interparietal sulcus (as on the right in the Eskimo brain) in $11 \%$; it was found complete and communicating with the interparietal (as on the left in the Eskimo brain) in $60 \%$ of the hemispheres. 
both sides with the Sylvian and on the left side also with the interparietal sulcus.

The left postcentral is very long, reaching to within $0.5 \mathrm{~cm}$. of the superior border of the hemisphere, where it connects, over an imperfectly submerged gyrus, with a vertical sulcus from the precuneus.

The connection of the postcentrals with the Sylvian is not effected by the trans-postcentral sulci.

The course of both postcentral sulci, and particularly of that on the left, is tortuous.

Each sulcus gives off during its course several incisures and small branches. On the left side, I.4 cm. above the Sylvian border, a quite deep branch passes backward through the supramarginal convolution and communicates with the superior terminal branch of the Sylvian. Three $\mathrm{cm}$. above the Sylvian the left postcentral connects, over a submerged gyrus, with the interparietal sulcus. Opposite this junction a branch, $1.4 \mathrm{~cm}$. long and looking like the anterior terminus of the interparietal, passes forward and slightly upward into the ascending parietal gyrus.

In its upper third the left retrocentral sulcus gives off three smaller branches. The lowest one of these passes backward; the middle one indents the ascending parietal gyrus and ends near the central sulcus; the third branch passes upward, ending in front of the dorsal termination of the paracentral fissure. The main limb of the sulcus then bends backward and runs toward the aforementioned connection with the precuneal.

The right postcentral sends off four branches or incisures, one of which, $2.0 \mathrm{~cm}$. long, passes backward from near the middle of the sulcus. Two and a half $\mathrm{cm}$. above the Sylvian the right postcentral connects, over a submerged but not deep fascicle, with the central fissure.

Superiorly the sulcus divides into two branches, the anterior $1.4 \mathrm{~cm}$., the posterior $2.4 \mathrm{~cm}$. in length, which surround, in the form of a broad $\mathrm{Y}$, the extremity of the paracentral sulcus. 


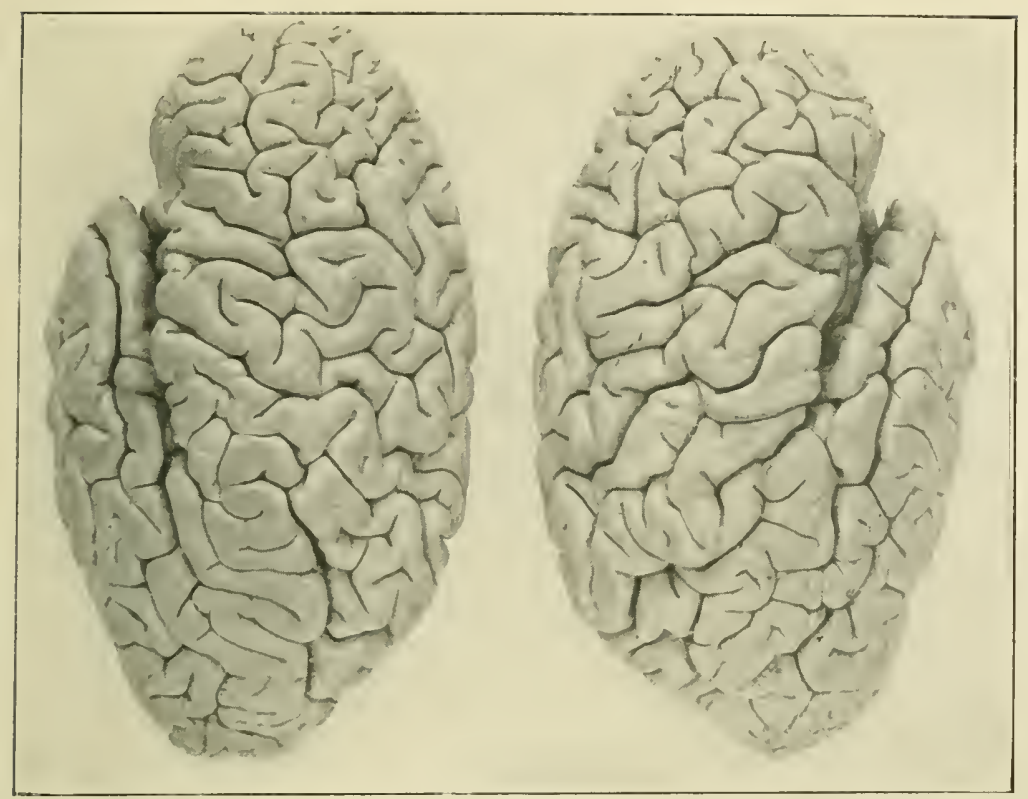

Lateral aspect

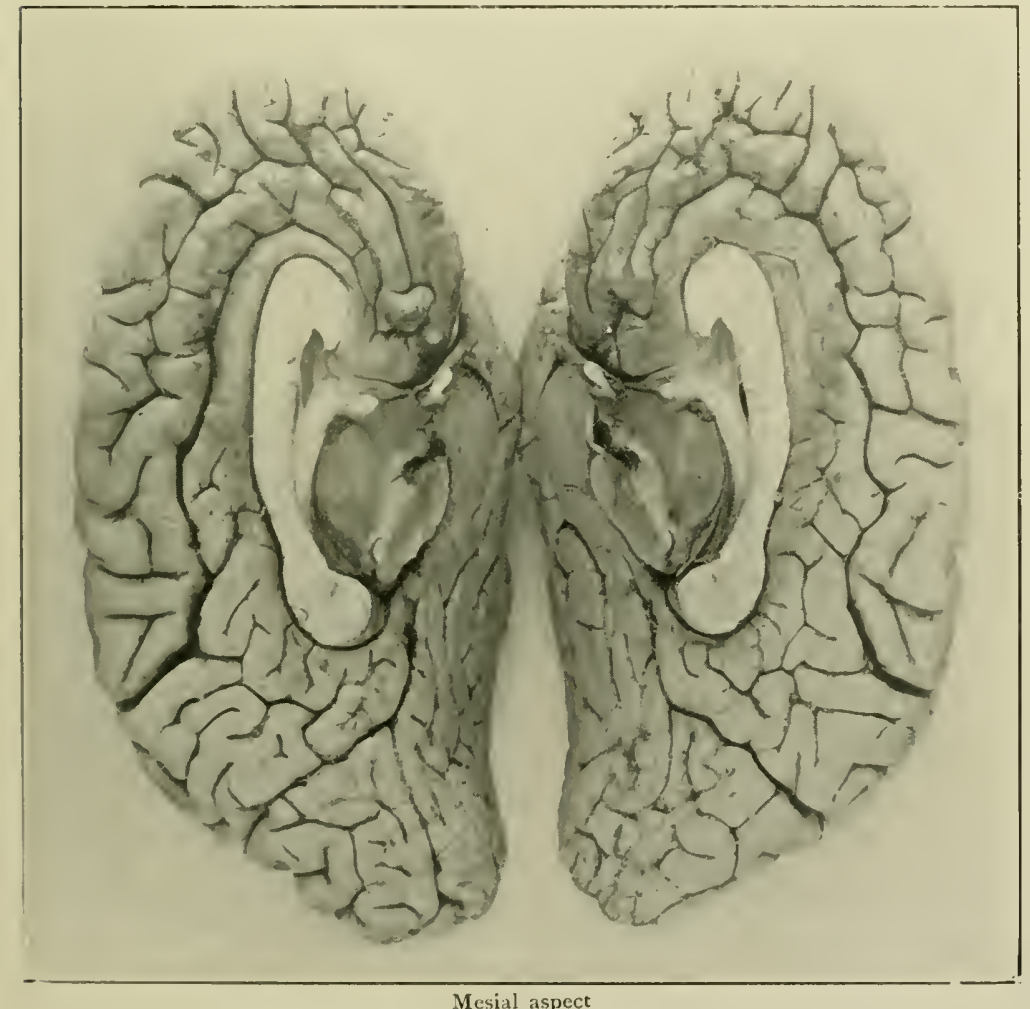

THE HEMISPHERES OF KISHU'S CEREBRUM 
Each postcentral shows in its course a number of more or less deep annectent fascicles.

The trans-postcentrals are in their usual position, but only that on the left (as was the case with the trans-precentrals) reaches the dorsal surface of the hemisphere.

The interparietal sulcus on the left commences, with a small $\mathrm{T}$, somewhat inferiorly and anteriorly to the end of the superior terminal Sylvian, $1.8 \mathrm{~cm}$. from the Sylvian bifurcation. Seven millimeters above its beginning the sulcus connects, over a submerged but not deep gyrus, with the postcentral. From this point the interparietal runs in a slight curve $4.2 \mathrm{~cm}$. upward and backward and joins freely the paroccipital sulcus. The interparietal gives off three larger branches, one of which runs downward, into the supramarginal, and the other two upward, into the superior parietal gyrus. There are within the sulcus several deep but no interrupting connecting bundles.

On the right side we find an anomalous deep furrow, uninterrupted except by very deep bundles, running from a point well down between the supramarginal and angular gyri, in a wavy course, parallel in the main with that of the postcentral sulcus and central fissure, to and $1.0 \mathrm{~cm}$. over the superior border of the hemisphere, ending on the precuneus.

From this furrow, above its middle, begins, over a depressed but still partly visible gyrus, the horizontal part of the interparietal. This is angular, but $0.8 \mathrm{~cm}$. long (in a straight line), and connects with the paroccipital.

The vertical furrow separates a stout and prominent convolution which runs parallel with the ascending frontal and ascending parietal gyri. The superior portion of the vertical furrow lies, independent of both, between the postcentral and the anterior curve of the paroccipital sulcus.

The minor parietal sulci will be mentioned with the description of the convolutions.

Occipital Lobe.-The anterior as well as the lateral occipital 
sulcus is fairly well represented on both sides. The anterior sulcus on the left connects with the ascending branch of the superior temporal, the anterior and lateral furrows on the right with the anomalous medio-temporal sulcus (q. v.). The lateral sulcus on the left is in the form of an $H$ and is without connections.

Temporal Lobe.-The sulci on the superior or intrasylvian surface of the lobe have been mentioned.

The lateral surface is higher on the right than on the left side. Its sulci are on both sides deep and the gyrations distinct.

The superior or first temporal sulcus begins on both sides in a line near the pole of the temporal lobe. It is preceded on the left by a small transverse furrow, on the right by a shallow depression.

The horizontal portion of the superior temporal is continuous on both sides. Its form is wavy on the left, more straight on the right side. It terminates on the left in a line $1.8 \mathrm{~cm}$. posteriorly to the Sylvian bifurcation and within $0.3 \mathrm{~cm}$. of the inferior terminal Sylvian. The ascending portion is separate. On the right the horizontal portion runs to a point about $1.2 \mathrm{~cm}$. posterior to the Sylvian bifurcation, connects with the inferior terminal Sylvian, and proceeds without interruption backward and upward as the ascending ramus.

The horizontal portion on the left connects, $1.6 \mathrm{~cm}$. before its posterior end, over a submerged but not deep gyrus, with a parallel, medio-temporal ${ }^{1}$ sulcus, $4.4 \mathrm{~cm}$. long, which separates the posterior half of the middle temporal gyrus into an inferior and a superior portion. The horizontal branch on the right connects, by means of a shallow transverse sulcus, with the second temporal, and more posteriorly as well as quite superficially with the medio-temporal.

The ascending branch on the left begins with a short vertical

${ }^{1}$ This term suggests itself from some similarity of this to the medio-frontal sulcus of Eberstaller. 
part that connects with the inferior terminal Sylvian. It runs backward and slightly upward, almost in line with the horizontal portion. It connects with the ascending part of the second temporal, and finally joins the anterior occipital sulcus.

On the right the ascending branch runs in an angular manner upward and backward, terminating a short distance below the paroccipital. This branch also has a shallow connection with the medio-temporal.

The medio-temporal sulcus is even better marked on the right than on the left. Beginning somewhat posteriorly to a vertical from the Sylvian bifurcation, it runs backward and upward, parallel with the ascending portion of the first temporal, to the occipital lobe. It connects with both the horizontal and ascending portions of the first temporal and also with the anterior as well as with the lateral occipital sulci.

Both the first and the medio-temporal sulci send off shorter branches and all show deep connections passing between the adjacent gyri.

The mean depth of the horizontal ramus of the left superior temporal sulcus is $I .8 \mathrm{~cm}$., that of the right, $2.1 \mathrm{~cm}$. The ascending rami are not so deep. The depth of the medio-temporals is less than that of the horizontal, but slightly greater than that of the ascending portion of the first temporal sulci.

The second or middle temporal sulcus is composed on each side of two separate segments; each of these shows some secondary ramifications.

The anterior portion on the left commences with a curve, passes in a wider curve backward and slightly upward, and terminates, nearly vertically below the central fissure, with several marked radiations. The posterior left segment begins in a $Y$ slightly above and posteriorly to the termination of the first part, and runs slightly downward and backward, to and along the inferior border of the hemisphere, terminating in a simple manner about $1.6 \mathrm{~cm}$., in a straight line, from the occipital pole, under the 
lateral occipital sulcus. Two and seven-tenths of a cm. anteriorly to its end this segment gives off, over a deep annectent fascicle, an ascending portion, which runs with several bends directly upward to connect with the ascending part of the first temporal sulcus.

On the right side, the first portion of the second temporal has its simple beginning $1.0 \mathrm{~cm}$. in a straight line from the pole of the temporal lobe; it passes $4.6 \mathrm{~cm}$. backward and ends in a small bifurcation. A short distance anteriorly to this bifurcation the sulcus communicates with the first temporal.

The posterior segment on the right begins a little posteriorly to the bifurcation of the first part, in the form of a doubly curved, nearly transverse line. This line bends, runs backward and downward, reaches the inferior border, sends a $1.3 \mathrm{~cm}$. long branch backward and inward into the third temporal gyrus, passes again to the dorsal surface of the hemisphere, and ends in a long $\mathrm{Y}$ figure, the lower extremity of which reaches to below the lateral occipital sulcus.

The third or basitemporal sulcus is unusually well developed, particularly on the left side.

The sulcus on the left is continuous, somewhat wavy in form, and measures $9.3 \mathrm{~cm}$. in length (in a straight line). It effects a shallow connection with the collateral.

The right sulcus consists of three large separate segments, which extend from near the pole of the temporal lobe to within $1.7 \mathrm{~cm}$. of the occipital pole. The segments send off a number of radiating branches, and the posterior one connects with the collateral.

On both sides the third temporal sulcus contains a number of submerged, more or less deep, annectent fascicles.

THE INSULA

The conformation of the surface of the island is quite similar on the two sides of the brain (figs. 57,58 ). 
The marginal or limiting sulci of the insula are very deep, especially anteriorly, and they are continuous, except over the antero-inferior extremity or pole of the insula.

The superior limiting sulcus communicates on both sides with the two branches of the presylvian; it also gives off on each side two short branches upward, and a deep short incisure downward, in to the insula itself. The average depth of the superior limiting sulci is $2.8 \mathrm{~cm}$., and in the course of each there are several strong annectent fascicles

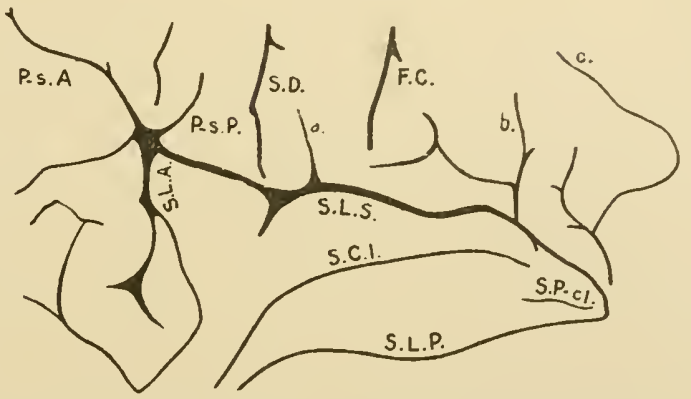

Fig. I7-Left insula. S.L.S., S.L.A., S.L.P., Sulci limitantes insulæ, superior, anterior, posterior: S.C.I." Sulcus centralis insulæ; S.P.c. 1., Sulcus post-centralis insulæ.

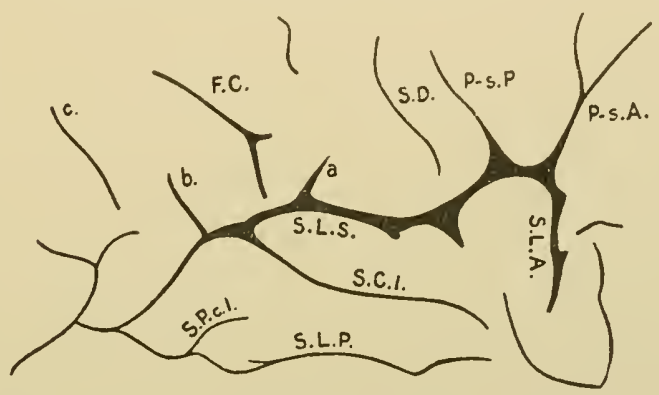

Frg. 28-Right insula. P-s.A., Presylvian anterior; P-s.P., Presylvian posterior: S.D., Sulcus diagonalis ; a, Trans-precentral sulcus; F.C., Central fissure ; b, Trans-postcentral sulcus ; c, Postcentral sulcus.

passing between the lobes of the island and the overlying opercula.

At the posterior inferior angle of the insula there are two strong, almost superficial annectent bundles, connecting the superior temporal gyrus with the insula; there is on each side also a strong connecting bundle between the anterior extremity of the posterior lobe of the insula and the superior temporal convolution.

The central sulcus of the insula is independent on the left, but it communicates with the superior limiting sulcus on the right side. The central sulci average only $0.5 \mathrm{~cm}$. in depth, and each shows anteriorly a submerged anastomotic fascicle. 
Besides the above sulci, each insula shows a small furrow which divides its posterior lobe into superior and inferior portions (sulci retrocentrales insulæ). There is also on each side a curving but not very deep sulcus which passes from below over the pole of the insula. This sulcus ends freely on the anterior lobule of the insula on the right, but joins the anterior limiting sulcus on the left side.

The anterior and posterior lobes of the insula are well defined and show the ordinary planes. Gyri breves fairly well marked.

\section{CONVOLUTIONS}

Frontal Lobe. Dorsal Surface.-The frontal gyri are rather more complex and tortuous than in average whites. The dorsal portion of the left superior frontal gyrus is slightly narrower in front than that of the right (left $2.85 \mathrm{~cm}$., right $3.05 \mathrm{~cm}$.), but somewhat broader posteriorly (left $2.8 \mathrm{~cm}$., right $2.5 \mathrm{~cm}$.). In about the middle, the left gyrus sends downward a prominent, shoe-like convolution, which indents the middle frontal gyrus. The dorsal parts of both superior frontal convolutions show, besides the segments of the sulcus mesialis of Cunningham, a considerable number of transverse depressions.

The middle or second frontal gyrus is on both sides of an irregular form and partly subdivided by the medial frontal sulcus. The posterior portion of the convolution on the left is especially well developed, and is separated from the more anterior portion by the vertical furrow. Both middle frontal gyri have numerous superficial and deep connections with the neighboring convolutions.

The inferior or third frontal gyrus is in this brain, contrary to the general rule, more extended antero-posteriorly and more redundant on the right than on the left side. This excess is especially marked in the right middle or triangular part (cap of Broca).

The convolution shows numerous connections; the orbital and 
triangular parts connect on both sides superficially with the middle frontal gyrus.

The ascending frontal convolution is somewhat stronger on the right than on the left. It is on both sides most slender in its middle fourth. It is on both sides continuous from the Sylvian fissure to the superior border of the hemisphere. Superficial connections.-On the left: a broad isthmus to the inferior frontal; a superficial annectent gyrus to the middle frontal; similar gyrus to superior frontal ; and, at the median border of the hemisphere, three superficial annectent gyri, one to the superior frontal, one to the paracentral, and one to the ascending parietal convolutions. On the right there is a broad superficial connection with the pars basilaris of the inferior frontal; and similar connections anteriorly with the middle and superior frontal, and superiorly with the paracentral and ascending parietal gyri.

Mesial Surface.- The left marginal gyrus is considerably higher than the right one. Its height is, from the orbital surface to the calloso-marginal fissure, on the left $2.2 \mathrm{~cm}$., on the right I. $8 \mathrm{~cm}$.; opposite the anterior pole, on the left $3.2 \mathrm{~cm}$., on the right $2.5 \mathrm{~cm}$.; and the average height of the upper part is, on the left $2.6 \mathrm{~cm}$., on the right $2.3 \mathrm{~cm}$. On both sides the marginal and the calloso-marginal gyri stand to each other, as to size, in an inverse relation.

The inferior extremity of each marginal gyrus is marked by the sulcus rostralis transversus and connects almost superficially with the inferior extremity of the limbic lobe (carrefour olfactif of Broca). The posterior extremity of the marginal gyrus communicates on the left by two superficial, on the right by one superficial and one deep, annectent gyri with the paracentral lobule.

As to the convolutions on the orbital surface of the frontal lobes, on the left the first and third frontal gyri, both markedly developed, join a little posterior to the middle of the surface, and 
the second frontal gyrus forms a wedge anteriorly between them. On the right, the second passes between the first and third gyri as a narrow band to the root of the olfactory nerve, where it joins the extremities of the other frontal convolutions.

The olfactory tracts and bulbs show nothing unusual.

The Parietal Lobe.-The ascending parietal gyrus is somewhat more voluminous on the left hemisphere (average width on the left about $1.2 \mathrm{~cm}$., on the right about $1.0 \mathrm{~cm}$.). The base of the convolution on the left measures, antero-posteriorly, $3.2 \mathrm{~cm}$., of that on the right $1.9 \mathrm{~cm}$. Both gyri show a constriction between their lower and middle thirds, and a marked development of the latter portion. The upper third is on each side slender, tapering, and not raised fully to the niveau of the neighboring parts.

The upper extremity of the gyrus connects superficially with the ascending frontal, paracentral, and superior parietal convolutions; the lower part connects, by means of submerged but not deep fascicles, with the ascending frontal and supramarginal gyri.

The superior parietal gyrus is throughout somewhat larger on the left side. Anteriorly it communicates on both sides superficially with the ascending parietal, and in a similar way posteriorly with the superior occipital convolution. Inferiorly there are numerous submerged fascicles of connection between the superior and inferior parietal gyri.

The left superior parietal convolution is separated by transverse sulci into two parts, the middle of which is very redundant. The right gyrus is somewhat similarly divided into two portions, of which the anterior is the more redundant.

The convolution shows on each side a number of lateral and surface indentures.

The paroccipital gyrus forms on each side a well-marked loop, which surrounds the extremity of the parieto-occipital fissure. The left gyrus is larger than the right one.

The inferior parietal convolution as a whole is larger on the 
right, compensating for the smaller size, on that side, of the superior parietal.

The supramarginal gyrus is fairly well defined on the left and is divided from the angular gyrus by a vertical branch proceeding from the interparietal sulcus (the sulcus intermedius primus, Jensen, Eberstaller). On the right side the marginal convolution is larger and more redundant; its operculum, or the triangular part between the two terminal branches of the Sylvian fissure, is especially well developed. The gyrus is bounded posteriorly by the inferior extremity of the vertical parietal sulcus.

The angular and postparietal gyri are nicely differentiated loops, separated by a vertical depression (sulcus intermedius secundus, Eberstaller) on the left, but are of irregular form and separated only from below by the extremity of the ascending branch of the superior temporal sulcus on the right side.

All the parts of the inferior parietal convolutions show minor lateral or surface indentations, and numerous deep as well as superficial connections.

The paracentral lobule is much better isolated anteriorly on the left than on the right. The left lobule is also slightly more redundant, though slightly less high and not any longer than that on the right side.

The surface of the left lobule is indented by two $\mathrm{Y}$-shaped and one lineal, that of the right by one $\mathrm{Y}$-shaped and two lineal, sulci.

Precuneus. - This lobule is separated completely on the left, incompletely on the right, from the limbic gyrus, by the posterior limbic or subprecuneal sulcus. The surface of the left precuneus is indented by four vertical sulci, two of which connect with the posterior limbic, while the other two pass over the border of the hemisphere, where the anterior communicates with the posterior terminal branch of the postcentral sulcus, and the posterior one forms the anterior boundary of the paroccipital gyrus. On the right, the precuneus presents a Y-shaped sulcus in connection 
with the intralimbic and postlimbic sulci, while its superior portion is indented by the terminus of the anomalous vertical parietal sulcus.

Both the paracentral lobule and the precuneus show numerous deep, besides the superficial, connections with the adjacent gyri.

Occipital Lobe.-The lobe measures, from the antero-inferior extremity of the cuneus to the occipital pole, on the left $4.7 \mathrm{~cm}$., on the right $4.9 \mathrm{~cm}$., which is respectively $26.1 \%$ and $27.4 \%$ of the whole length of the hemisphere (see also additional measures).

The gyration of the lobe in the Eskimo brain under consideration is not inferior to that met ordinarily in whites. It presents, as is often the case, some difficulty to analysis, but no very extraordinary features.

The cuneus is bounded by almost straight lines. It is lower, but longer, on the right hemisphere. Its superior border is indented on the left by two, on the right by one incisure. Its surface shows on the left an independent triradiate sulcus with branching extremities; on the right a large, somewhat $\mathrm{Y}$-shaped sagittal sulcus, which connects with the parieto-occipital, and a quadriradiate sulcus, one of whose branches connects with the collateral.

Temporal Lobe.-The superior temporal gyrus is considerably stronger on the right than on the left side (mean height of the left, $0.8 \mathrm{~cm}$.; of the right, I. I cm.). The left gyrus is particularly slender and is slightly depressed in its middle.

The left convolution is interrupted by one of the transtemporal furrows which connects with the superior temporal sulcus.

The right superior temporal gyrus appears to be composed of three imperfectly separated portions, namely, a long anterior part, reaching to within $1.0 \mathrm{~cm}$. of the bifurcation of the Sylvian, separated from the rest of the gyrus by two incisures (one superior and one inferior), which almost meet, and a shallow depression. The more anterior of the following two parts is in the 
form of a larger oblong lobule, situated between the depression just mentioned and the connection of the inferior terminal Sylvian with the superior temporal sulcus. The third part is a small, partly depressed isle projecting from the second part into the Sylvian and separated from that part by a shallow sulcus.

The middle or sccond temporal gyrus is also more voluminous on the right side; both are quite redundant.

The anterior half of the convolution on the left is curved, on the right straight and wedge-shaped. The posterior half on each side, somewhat less redundant, is divided into two parallel, nearly equally strong portions by the secondary medio-temporal sulcus.

The anterior portion of the right gyrus is indented by two vertical sulci proceeding from the second temporal; the anterior of these connects with, while the posterior reaches very near to, the first temporal sulcus.

The superior posterior portion of the right gyrus is separated by a connecting branch between the first and medio-temporal sulci.

Both gyri show a number of more or less marked lateral incisures and a few minor surface furrows.

The inferior or third temporal gyrus lies, on both sides of this Eskimo brain, almost wholly on the inferior surface of the temporal lobe. It is easily isolated.

The gyrus is on both sides strongest in about its middle third, its anterior and posterior extremities tapering a little. It is on each side incised by a number of incisures which pass into it from both the second and third temporal sulci, but it is nowhere totally interrupted. In its middle enlargement the gyrus is on each side indented by an independent ramifying sulcus, which on the left has the form of a double joined $Y$, and on the right approaches the form of $H$. Excepting the anterior and posterior, the gyrus has one superficial connection on the left (with the anterior portion of the second temporal) and two on 
the right side (with the anterior part of the second temporal and with the fusiform lobule).

The fusiform gyrus, well defined on both sides, is throughout more voluminous on the right. The left gyrus shows, near its posterior third, a shallow interruption. The borders of both convolutions are indented by a number of more or less pronounced incisures. The gyri show numerous submerged connections with the third temporal and the lingual convolutions.

The lingual gyrus, well defined, connects on both sides, anteriorly, superficially, and freely, with the gyrus hippocampi; posteriorly, near the occipital pole, with the fusiform lobules.

The gyrus is partly divided on both sides into halves by a branch from the collateral fissure. The anterior portions are somewhat tongue- or pear-shaped, the tapering ends connecting with the hippocampal gyri, and each is indented by a quite prominent sagittal sulcus. The posterior extremity of this sulcus, on the right, connects with a branch from the collateral. The posterior half on the left is nearly straight and more slender than the anterior one; that on the right forms a marked loop. The surface of the posterior portions, also, is indented on each side by a small, mainly sagittal depression.

THE LIMBIC LOBE

This lobe differs remarkably on the two sides. It is much larger over almost its entire extent on the right side, as will be indicated by the following measures (taken between the sulcus of the callosum and the external boundary of the gyrus):

Antero-inferiorly, below the rostrum (above Broca's

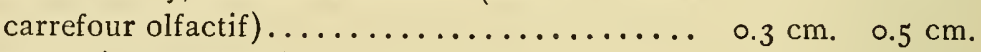
Anteriorly (horizontally)............... $0.5 \mathrm{~cm} . \quad 1.0 \mathrm{~cm}$. Superiorly, beneath the first frontal or marginal gyrus...................... $0.85 \mathrm{~cm} . \quad 1.5 \mathrm{~cm}$. Superiorly, below the paracentral lobule....... $\quad 1.5 \mathrm{~cm}$. $2.1 \mathrm{~cm}$. Superiorly, below the precuneus............ $2.0 \mathrm{~cm} . \quad 2.6 \mathrm{~cm}$. Posteriorly, opposite the cuneus............. I. $6 \mathrm{~cm} . \quad \mathbf{I} .4 \mathrm{~cm}$. 
The lobe begins on both sides at the well-developed olfactory lobule or space of Broca, below the rostrum of the callosum. Its ascending portion and a part of its horizontal portion are entirely smooth on the left; on the right side the external boundary of these parts shows many depressions, and the horizontal part is traversed by the previously described sagittally running, shallow sulcus.

All the parts of the limbic lobe behind the line which bounds anteriorly the paracentral lobule are much more developed than the parts anterior to this line. On the left this posterior portion of the lobe is traversed by a number of transverse sulci and has the appearance of being composed of four or five loops lying in close apposition. On the right, there is a somewhat similar formation of loops, but their outline is more angular. Directly beneath the splenium both lobes become very narrow and soon after blend with the hippocampal convolutions.

Deep bundles connect the limbic lobe on each side with the mesial part of the first frontal gyrus and the parietal lobule. The connections of the lobe with the precuneus are on the left all submerged, though not deep, while on the right side besides these deep bundles there is also, posteriorly, a superficial annectent gyrus between the two structures. A few deep fascicles pass between the lobe and the cuneus and lingual gyrus.

\section{HIPPOCAMPAL GYRUS}

This gyrus is somewhat larger on the right side. It is almost isolated externally on the right, only a small annectent gyrus passing from it, between the fissura rhinica and the inferior temporal sulcus, to join the fusiform convolution. On the left side this connection is broader. The surface of the gyri is smooth. Both gyri connect superficially with the lingual convolutions. The uncus is well marked on both sides.

The parts within the limbic lobe show nothing extraordinary. The callosum is exceptionally strong and very nearly equal on the two sides. Its measurements are as follows: 
Diameter antero-posterior maximum............ $7.9 \mathrm{~cm}$.

Maximum height of anterior enlargement......... I.45 $\mathrm{cm}$.

Maximum height of posterior enlargement.......... I.5 $\mathrm{cm}$.

Maximum height between the enlargements.......... I.o $\mathrm{cm}$.

Minimum height between the enlargements........ $0.75 \mathrm{~cm}$.

The dentate gyrus is well differentiated and the fimbria well developed.

\section{Cerebellum, Pons, Medulla}

All these parts appear to be very well developed; they are symmetrical and present no gross deviation from the shape and conformation of the same parts as generally observed in whites.

\section{Measurements of Cerebellum}

Height maximum................... $5.7 \mathrm{~cm}$.

(in fresh brain.............. $5.8 \mathrm{~cm}$. )

Diameter antero-posterior maximum ${ }^{2} \ldots \ldots \ldots \ldots \ldots \ldots .8 \mathrm{~cm}$.

(in fresh brain ................. $7.0 \mathrm{~cm}$. )

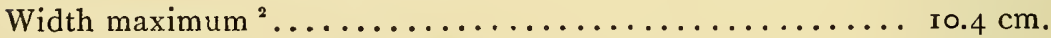

(in fresh brain................. I0.6 $\mathrm{cm}$.)

Antero-posterior length of worm ............. $4.3 \mathrm{~cm}$.

Maximum height of worm ................. $4.0 \mathrm{~cm}$.

Maximum depth of anterior fossa............. $2.2 \mathrm{~cm}$.

Maximum depth of posterior incisure............ I. $3 \mathrm{~cm}$.

Depth to the top of the worm (from a plane corresponding to the highest points on each cerebellar hemisphere)..... $1.3 \mathrm{~cm}$.

\section{Measurements of the Pons}

Width maximum....................... $3.5 \mathrm{~cm}$.

Height (vertical) from fourth ventricle............ $2.9 \mathrm{~cm}$.

Length (antero-posterior)..................

\section{Measurements of the Medulla}

Thickness maximum infero-superiorly ........... I. $8 \mathrm{~cm}$. Thickness maximum laterally ............... $2.0 \mathrm{~cm}$.

1 About $1.0 \mathrm{~cm}$. from the median line on each side.

${ }^{2}$ At about the junction of anterior third with posterior two thirds. 
THE CEREBELLUM

The great horizontal fissure encircles the organ completely. It averages $1.6 \mathrm{~cm}$. in depth. On its bottom many slender rods are seen to pass from one part of the cerebellum (superior) to the other (inferior), all directed obliquely outward. (There are similar rods within all the other sulci.)

All the usual lobes of the upper surface (as well as all the divisions of the worm) are present and well developed. There are two lobules situated laterally to the lingula (which faces forward); these two lobules are joined $2 \mathrm{~cm}$. outward to the alæ lobuli centralis. These last are very small and hidden. The lingula, with the wings and the central lobule, gives a very good appearance of a moth, with wings converging upward.

Central lobe small. Folium cacuminis double; uvula consists of eight segments of which the last two (in pyramid) are small.

The pyramid is breast-shaped, with the apex posteriorly and a deep notch anteriorly; into this notch are received the last two little segments of the uvula. The lateral masses are anteriorly separated and form two distinct parts, applied over the extremity of the uvula. The parts connect anteriorly by deep annectent fascicles with the cerebellum. Tuber portions small. None of the lobes and parts of the lower surface and lower worm present anything extraordinary.

Summary of the Main Peculiarities of Kishu's Brain

As a whole, this Eskimo brain is heavier and larger than the average brain of white men of similar stature. The excess of weight over the averages of both Broca's and Manouvrier's specimens (averages which agree well with those obtained by Bischoff, Boyd, Sims, Huschke, and other observers) amounts to almost I50 grammes.

As to size, the average antero-posterior diameter of the white male brain ranges, according to Huschke, between 16.0 and 17.0 
$\mathrm{cm}$. (mean $16.5 \mathrm{~cm}$.), and the average maximumlateral diameter I $4.0 \mathrm{~cm}$. The mean of these measures, which largely removes the disturbing element of the shape of the brain, is 15.25 . The crude measurements of Kishu's brain amount, for the length, to $18.0 \mathrm{~cm}$. for the left and $17.9 \mathrm{~cm}$. for the right hemisphere, and $13.6 \mathrm{~cm}$. for the maximum breadth of the cerebrum. These figures give us the mean of 16.5 , which is to that in whites as IOS.2 to 100.

The different parts of the brain do not show the same relative weight proportions as they do in the average white brain, and the same is true of the relative size of the principal parts of the cerebrum. The cerebellum, and particularly the pons with the bulb, is relatively somewhat heavier in Kishu than in whites; while as to the main cerebral parts the most remarkable feature is the relative smallness of the parietal portion (see additional measurements).

In its external conformation this Eskimo cerebrum rather exceeds that of an average white male in the number, extent, and depth of the sulci, and in the complexity of the gyrations.

Both hemispheres, and especially the right one, show a generally marked tendency to vertical gyration. The left side shows one, the right two, large, anomalous, composite, vertical furrows. The gyration of the left hemisphere is in general somewhat more complex than that of the right one.

The pars triangularis of the inferior frontal convolution, the temporal lobe, inferior parietal gyrus, and limbic lobe are all larger on the right than on the left; on the other hand, the mesial part of the superior frontal gyrus, the middle frontal gyrus, the paracentral lobule, the precuneus, and the mass of the occipital lobe, are larger on the left than on the right side.

There is a great length of the postcentral sulci, particularly of that on the left. The left Sylvian (main limb) is longer, the left central fissure is situated (in a horizontal direction) slightly more posteriorly and is slightly more vertical than the right. There is 
a bilateral, longitudinal division of the mesial part of the superior frontal gyrus and a tendency on the right to a similar division of the limbic lobe ; and on each side there is a pronounced mediotemporal sulcus, dividing sagittally the posterior part of the middle temporal convolution.

Besides those enumerated, there are many other interesting minor features of the brain which need not be repeated.

\section{Comparative Notes}

The collection in the Medical Department of Columbia University includes, besides that of Kishu, the brains of three other Eskimo of the same party and originally from the same locality (Smith sound). One of these specimens is from Nooktah, a man older than Kishu; another from Atana, a woman of about the same or a little more advanced age than Kishu; and the third from Avia, a girl of ten to twelve years of age. A detailed report on these three brains is being prepared, as hitherto mentioned, by Mr E. A. Spitzka ; my independent work on the same extends. over those points only which are of particular interest in connection with the specimen here described, including the more important measurements.

The general gyration in these additional Eskimo brains, compared with that in average adult whites, is very good, particularly over the frontal lobes, in Nooktah, good in Atana, rather simple in Avia. In all the external conformation is more complex on the left hemisphere. The frontal gyration in Nooktah is not less complex than that in Kishu, but the whole brain of the latter is more developed and richer.

The insulæ are both quite exposed anteriorly in Atana, less so in Avia, and covered, or very nearly so, in Nooktah as well as in Kishu.

The ascending frontal gyri are both very strong in Atana, the ascending parietal gyri on both sides and the ascending frontal on the right in Avia. 
The anterior and posterior portions of the presylvian are separate in all three brains, as in that of Kishu.

The central fissure, which in Kishu commenced in the Sylvian, has a similar origin on the right side in Avia; in all other instances it reaches near to the Sylvian. The superior termination of the fissure reaches the superior border in Nooktah and on the right in Atana, and passes slightly to moderately over it on the left in Atana and on both sides in Avia. In the girl the course of the fissure is remarkably vertical.

A longitudinal division of the mesial part of the superior frontal gyrus, found in Kishu, is also present complete on left, interrupted on right, in Nooktah; slightly incomplete on left, small traces on right, in Atana; and on the right in Avia.

The limbic lobe shows traces of longitudinal division, as on the right in Kishu, on the right in Nooktah, and on the left in Avia. The lobe that shows the traces of division is in both cases, so far as these traces extend, higher than that of the opposite side, as was also the case in Kishu.

A furrow somewhat similar to the pre-precentral vertical furrow in Kishu is seen on the right in Nooktah, while sinuosities, somewhat similar to the right vertical post-postcentral one in Kishu, occur on the left in Atana and on the right in Avia.

The postcentral sulcus is single in all cases, except on the left in Avia, where it exists in two portions.

The temporal lobe is slightly higher on the left side in Nooktah and Avia (see the measurements). The first temporal gyrus is in all cases moderately to well developed. The medio-temporal sulcus, though present in segments in Nooktah and Atana, is by no means as clearly distinguishable as in Kishu.

Broca's cap, or that part of the inferior frontal convolution situated between the two portions of the presylvian, is, contrary to what was the case in Kishu, in all these brains better developed on the left side. 
The extremities of the occipital lobes are in all three brains of about equal size and not disproportionate as in Kishu.

Additional and Comparative Measurements

The subject of brain measurements is still in its infancy. Although many brains have been measured, particularly since Huschke and Broca, there is yet no standard system of encephalometry comparable with that of the measuring of the head or cranium. Every author of importance has thus far chosen his own points from which to measure, and there is no regulation of either the methods or instruments. There is no more important part of the body and at the same time no part with which more care and accuracy are required in measuring, than the brain, and these two conditions ought to prompt an early and thorough systematization of procedure. As it is, the brain measurements of one author can scarcely be compared or joined with those of any other.

The most disturbing factors in measuring the brain are, first, its softness and the consequent yielding and deformation of the organ when removed from the cranial cavity; this difficulty can now be effectually counteracted by a formaline-alcohol or forma. line hardening of the organ before the opening of the skull.

The second important factor, which thus far has not received sufficient attention, is the different shape of the brain in different individuals and especially in different races. No one would think of comparing, or uniting in a series, the dimensions of a dolichocephalic with those of a brachycephalic skull, and similar distinctions should be established in brain measurements.

The choice of instruments is very important. Even if the tape only be used, considerable differences in the measurements are obtained according to the width of the same.

Some, and perhaps many, of the measurements of the brain carry valuable indications which we today do not appreciate. The knowledge of the organ will certainly progress, and meas- 
urements taken with care, even if not essential now, may in the future be found of value.

A more detailed discussion here of these important matters would be somewhat irrelevant to the subject of this paper. The above remarks are thought to be a proper introduction to the following figures and comparisons.

The measurements of Kishu's brain, which was carefully preserved, between cotton, in a mixture of formaline and alcohol, are, as I have certified on the skull, almost absolutely correct. The brains of Nooktah, Atana, and Avia were preserved in a weak solution of formaline. Nooktah's brain is fairly well preserved and its measurements are apparently quite correct; the brains of Atana and Avia, however, have suffered a rather considerable change in form, and the absolute measurements of these specimens have but little meaning. The relative proportions of the various parts of the cerebrum were undoubtedly much less affected than the absolute measurements and are probably still fit for consideration.

The surface measurements were taken by a tape $0.8 \mathrm{~cm}$. broad, while the diameters were obtained on a graduated plane (Mathieu's) and by the accurate sliding compass used in osteometry. Three repeated measurings gave fairly even, though in but very few instances exactly the same, results.

The points from which the various dimensions were taken and the methods will be explained with each measurement.

Measurements

APPROXIMATE LENGTH OF THE LINES OF NORMA ANTERIOR, KISHU :

$$
\text { Left }
$$

Antero-lateral lines........ I I.5 cm.

Anterior lines ${ }^{1} \ldots \ldots \ldots \ldots \ldots$

Postero-lateral lines....... $8.2 \mathrm{~cm}$.

$8.3 \mathrm{~cm}$.

$$
\begin{gathered}
\text { Right } \\
\mathrm{I} 0.3 \mathrm{~cm} \text {. }
\end{gathered}
$$

Posterior lines ${ }^{2} \ldots \ldots \ldots \ldots \ldots$.

1 Taken between two cardboards applied to the antero-lateral planes of the brain, the line measured touching the anterior surface of the frontal lobes.

${ }^{2}$ Obtained in a way similar to that of the anterior lines. 
MAXIMUM LENGTH OF THE HEMISPHERES

Left

Kishu................ I $8.0 \mathrm{~cm}$.

Nooktah............. I $6.8 \mathrm{~cm}$.

Atana................. (I $7.1 \mathrm{~cm}$.

Avia ..................... (I $5.3 \mathrm{~cm}$.
Right

$17.9 \mathrm{~cm}$.

I $7.0 \mathrm{~cm}$.

(I $7 . \mathrm{s} \mathrm{cm}$. )

$(15.3 \mathrm{~cm}$.

In one of the males the length of the left exceeds slightly that of the right hemisphere, while in the other male the condition is reverse; in the two females the length of both hemispheres is equal.

In whites the left hemisphere is almost generally slightly longer (Eberstaller,' Cunningham ${ }^{2}$ ).

MAXIMUM WIDTH OF THE CEREBRUM ; CEREBRAL INDEX, COMPARED TO CEPHALIC (on the living).

\begin{tabular}{|c|c|c|}
\hline & $\left(\frac{\text { Breadth } \times \text { xo }}{\text { Length }}\right.$ & $\left.\frac{\text { eadth of Head } \times 100}{\text { Length of Head }}\right)$ \\
\hline Kishu ..... I $3.6 \mathrm{~cm}$. & 75.8 & 76.26 \\
\hline Nooktah.... I I.I cm. & $77 \cdot 5$ & $8 \mathrm{I} \cdot 4$ \\
\hline $\operatorname{Atana} \ldots . .(\mathrm{I} 2.3 \mathrm{~cm})$. & $(71.9)$ & 80.6 \\
\hline Avia ........ ( I $.6 \mathrm{~cm})$. & $(75.8)$ & 72.9 \\
\hline
\end{tabular}

It can be seen that while the brains of Kishu and Nooktah have kept nearly the same relative proportions as they must have had in life, that of Atana became relatively longer and narrower and that of Avia shorter.

\section{ARC MEASURES ALONG THE SUPERIOR BORDER ${ }^{3}$}

a. Anterior Point (Cunningham) to Central Fissure.

$$
\text { Left Right }
$$

Kishu. . I $7.0 \mathrm{~cm}$. or $63.0 \%, \quad 17.7 \mathrm{~cm}$. or $65.1 \%$ of the total mesial length. Nooktah $16.7 \mathrm{~cm}$. or $66.5 \%, \quad 16.7 \mathrm{~cm}$. or $64.5 \%$.

Atana.. (I $5.3 \mathrm{~cm}$. or $59.8 \%),($ I $5.0 \mathrm{~cm}$. or $60.5 \%)$.

Avia.. (I $5.5 \mathrm{~cm}$. or $64.6 \%$ ), (I $5.0 \mathrm{~cm}$. or $62.5 \%$ ).

${ }^{1}$ Eberstaller, Das Stirnhirn, Wien and Leipzig, I 890.

${ }^{2}$ Cunningham, D. J., "Contrib. to the Surface Anatomy of the Cerebra] Hemispheres." Roy. Irish Acad., Cunningham Mem,, v11, I892. All the following references to Cunningham relate to this work.

${ }^{3}$ Eberstaller measured from the anterior perforated space to the occipital pole. Cunningham, whom I follow, takes the same measures "from a point on the upper or mesial border which corresponds to the level of the outer part of the superciliary 
This relative length of the precentral part to the total mesial arc, this latter being taken as 100 , is termed by Cunningham the frontal or fronto-Rolandic index, and is in whites, according to the same author (pp. 55, 175), as follows :

In $125 \frac{1}{2}$ to $6 \frac{1}{2}$ mos. embryos.......... $5^{2.7}$

In 24 full-term fœtuses............ 53.5

In 82 adults.................... 53.3

In apes and monkeys from 55.9

in chimpanzee to 45.4

in mangaby.

b. Central to Parieto-Occipital Fissure

Left Right

Kishu.... $4.3 \mathrm{~cm}$. or $15.9 \%, 4.3 \mathrm{~cm}$. or $15.8 \%$ of the mesial arc. Nooktah... $3.9 \mathrm{~cm}$. or $15.5 \%, \quad 5.0 \mathrm{~cm}$. or $19.3 \%$ of the mesial arc. Atana..... $(5.8 \mathrm{~cm}$. or $22.7 \%),(5.2 \mathrm{~cm}$. or $21.0 \%)$ of the mesial arc. Avia...... (5.I cm. or $21.2 \%),(5.3 \mathrm{~cm}$. or $22.1 \%)$ of the mesial arc.

Cunningham, who terms the proportion of the central parietooccipital fissure segment to the whole mesial arc (this being taken as IOO, the parietal index), obtained the following in whites (p. 55):

Parietal Index

In $125 \frac{1}{2}$ to $6 \frac{1}{2}$ mos. embryos........... 28.5

In 24 full-term fotuses .............. 25.7

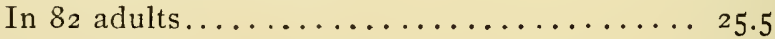

In 4 orangs $\ldots \ldots \ldots \ldots \ldots \ldots \ldots \ldots \ldots \ldots \ldots \ldots \ldots$

Further, in 4 chimpanzees............... I9.9

In 5 cynocephali.................... 22.6

In 5 macaques.................. 19.0

In 7 cebi $\ldots \ldots \ldots \ldots \ldots \ldots \ldots \ldots \ldots \ldots \ldots \ldots \ldots .6 .6 .6$.

margin of the frontal lobe. This border is very far from being horizontal. Its outer part is on a much higher level than the inner part. As it is traced inwards it is seen to take a sudden curve downwards towards the cribriform plate of the ethmoid bone, where it merges with the mesial border. A line drawn horizontally inwards from the high outer part of the superciliary border of the frontal lobe cuts the mesial border of the cerebrum at the point which I arbitrarily selected as the anterior end of the cerebrum. It lies, as a rule, just below the most projecting part. Behind I took the most prominent part of the occipital pole." "The first of these points may be distinguished as the frontal point, and the latter as the occipital point. Further, the distance between these two points measured along the upper border of the hemisphere may be termed the mesial length." (Loc. cit., pp. xi, xii.)

Cunningham's anterior point has no advantage over that of Eberstaller, and I employ it only to enable comparison of my own with Cunningham's indices. 
c. Parieto-occipital Fissure to most Prominent Point on the Occipital Pole
Left
Right

Kishu.....5.7 cm. or 2 I. I $\%, 5.2 \mathrm{~cm}$. or I9. I \% of the mesial arc. Nooktah... $4.5 \mathrm{~cm}$. or $17.9 \%, 4.2 \mathrm{~cm}$. or $16.2 \%$ of the mesial arc. Atana .... $(4.5 \mathrm{~cm}$. or $17.6 \%),(4.6 \mathrm{~cm}$. or $18.5 \%)$ of the mesial arc. Avia..... (3.4 cm. or $14.2 \%),(3.7 \mathrm{~cm}$. or $15.4 \%)$ of the mesial arc.

Cunningham terms the relative distance of the parieto-occipital fissure from the most prominent point in the occipital pole the occipital index, and obtained for whites (pp. 55, 56):

In $\mathrm{I} 25 \frac{1}{2}-6 \frac{1}{2}$ mos. embryos ......... I 8.8

In 24 full-term fœtuses.......... 20.8

In 82 adults................ 2 I.2; also, in

4 orangs.................... 23.2

4 chimpanzees............... 24.2

5 cynocephali............... 29.7

5 macaques.................. 31 .

7 cebi...................... 33.0.

Among adult whites, in 45 men the occipital index was 20.8 ;

in 35 women the occipital index was 21.7 .

The total mesial arc (from the anterior point, Cunningham, to the most prominent point on occipital pole) was:

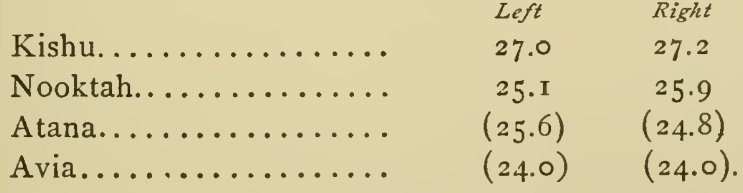

The above indices show in the Eskimo some remarkable features which are undoubtedly more than individual variations. There are in all the Eskimo, but especially in the men, relatively high frontal and low parietal indices. The parietal indices in the two females and the occipital indices in the two males and the adult female, though also lower, approach more those in whites. There is in the four Eskimo, according to these surface measurements, relatively a more extended superior frontal and a more restricted superior parietal area than in the average whites.

${ }^{1}$ Compare in this connection, and with the horizontal dimensions that follow, the seemingly conflicting measures of Féré, Passet, and Giacomini, referred to by Dejerine, 
There is another and somewhat more accurate way in which the dimensions of the main parts of the cerebrum may be determined. If the hardened hemisphere is placed on the graduated board in such a way that the most prominent frontal and occipital points are on a line which runs lengthwise along the middle of the board, we can then secure, by means of two vertical planes and a rod-measure or an ordinary compass, any desirable horizontal distance from the cerebral extremities. Such distances, compared with the total horizontal length of the hemisphere, give indices which are somewhat more accurate and perhaps not inferior in value to those obtainable by surface measuring. Following this procedure on the Eskimo brains, I have obtained the following figures and proportions:

a. Horizontal Length, Frontal Pole to Superior Extremity of Central Fissure

$$
\text { Left Right }
$$

Kishu.... $10.9 \mathrm{~cm}$. or $60.6 \%, \quad$ 10.8 cm. or $60.4 \%$

of the length of the hemisphere.

Nooktah. . $10.9 \mathrm{~cm}$. or $64.9 \%, \quad$ 10.7 cm. or $62.9 \%$

of the length of the hemisphere.

Atana..... (9.6 cm. or $56.1 \%),($ ro. $0 \mathrm{~cm}$. or $58.5 \%)$

of the length of the hemisphere.

Avia...... (9.8 cm. or $64 . \mathrm{r} \%), \quad(9.3 \mathrm{~cm}$. or $60.8 \%)$

of the length of the hemisphere.

b. Horizontal Distance, Superior End of Central to Parieto-occipital Fissure ${ }^{1}$

Left Right

Kishu... 4. $4 \mathrm{~cm}$. or $22.8 \%, 4.0 \mathrm{~cm}$. or $22.3 \%$

of the length of the hemisphere.

Nooktah. . $2.3 \mathrm{~cm}$. or $3.7 \%, 3.5 \mathrm{~cm}$. or $206 \%$

of the length of the hemisphere.

Anat. d. Centres Neryeux, Paris, I895, p. 249. The coincidence of the relatively somewhat small occipital with relatively small parietal lobes is quite curious. Gratiolet (quoted by Cunningham, p. 59) states that in man the occipital lobe is extremely reduced; and formulates the law that "the more highly organized a member of the group is, the smaller is the relative size of the occipital lobe." Quite as striking, however, is the small relative size of the parietal lobe in the ape.

1 The measurements are taken between the points of intersection by the fissures of the superior border of the hemisphere. Where the parieto-occipital fissure bifurcated before reaching the superior border (left in Atana, right in Avia), the measurement was taken to a prolongation of the main limb of the fissure. Same with surface measurements. 


\begin{abstract}
Left Right
Atana.. (5.1 cm. or $29.8 \%),(4.6 \mathrm{~cm}$. or $26.9 \%)$

of the length of the hemisphere.

Avia.... (4.0 cm. or $26.1 \%),(4.4 \mathrm{~cm}$. or $28.8 \%)$

of the length of the hemisphere.
\end{abstract}

c. Horizontal Distance, Parieto-occipital Fissure to Occipital Pole

Left Right

Kishu.... $3.0 \mathrm{~cm}$. or $16.7 \%, 3.1 \mathrm{~cm}$. or $17.3 \%$

of the length of the hemisphere.

Nooktah. $3.6 \mathrm{~cm}$. or $21.4 \%, \quad 2.8 \mathrm{~cm}$. or $16.5 \%$

of the length of the hemisphere.

Atana... (2.4 cm. or $14.0 \%),(2.5 \mathrm{~cm}$. or $14.6 \%)$

Avia.... (1.5 cm. or $9.8 \%),(1.6 \mathrm{~cm}$. or $10.5 \%)$

of the length of the hemisphere.

of the length of the hemisphere.

These measurements show almost generally a higher relative proportion of the region between the central and parieto-occipital fissures than was the case with the surface measurements, which indicates that the region is relatively more flat than the others.

Two more notable facts shown by both the arc and the horizontal measurements are a very small parietal and a large occipital portion on the left in Nooktah and the small occipital portions in Avia.

A more detailed study of the figures shows that, so far as their size is concerned, the main portions of the cerebrum tend to compensate each other.

DISTANCE OF THE LOWER EXTREMITY OF THE CENTRAL FISSURE FROM THE FRONTAL POLE

Cunningham measured this distance over the surface of the frontal lobe, comparing the dimension thus obtained with the entire arc running in the same line from the mesial border of the anterior to that of the posterior extremity of the hemisphere. I have followed the same method, but have supplemented it with the horizontal distance, as with the preceding measurements. The results are as follows: 
Surface Distance of the Base of the Central Fissure from the Mesial Border of the Anterior Extremity

a. Arc to the base of central fissure. b. Complete lateral arc.

Centesimal relation of $a$ to $b$.

\begin{tabular}{|c|c|c|c|c|c|c|}
\hline & Left & Right & Left & Right & Left & ight \\
\hline & $10.8 \mathrm{cr}$ & I I.I cm. & $25.2 \mathrm{~cm}$. & $24.5 \mathrm{~cm}$. & 42.9 & $45 \cdot 3$ \\
\hline & 10.70 & $10.5 \mathrm{~cm}$ & $23.3 \mathrm{~cm}$ & $23.1 \mathrm{~cm}$. & $45 \cdot 9$ & \\
\hline & & I0.6 & $(22.9$ & $23 . \mathrm{I} \mathrm{cn}$ & $(48.9$ & \\
\hline & $(8.0$ & $8.6 \mathrm{~cm})$. & $(2 \mathrm{I} .3 \mathrm{~cm}$. & $2 \mathrm{I} . \mathrm{I} \quad \mathrm{cm})$. & $(37.6$ & \\
\hline
\end{tabular}

The centesimal relation of $a$ to $b$ is termed by Cunningham (p. I79) the lower Rolandic index and was:

In 17 adult whites, males $\ldots \ldots \ldots \ldots \ldots \ldots \ldots \ldots \ldots \ldots \ldots \ldots$

In 20 adult whites, females.............. 43.0

The index differed but little in children and human embryos; in apes and monkeys it ranged (p. I75) from 39.2 in the orang and chimpanzee to 43.8 in cebus.

The horizontal distance of the base of the central fissure from the frontal extremity, and its centesimal relations to the length of the hemisphere, are as follows :

a. Distance to base of central fissure.

Left

Kishu........ $7.3 \mathrm{~cm}$.

Nooktah....... $7.6 \mathrm{~cm}$.

Atana......... $\quad(8.3 \mathrm{~cm}$.

Avia......... $\quad(5.4 \mathrm{~cm}$.
Centesimal relation of $a$ to length of hemisphere

Left Right

$40.6 \quad 36.3$

$45.2 \quad 44.1$

(48.5

( 35.3 $38.6)$.

\section{LENGTH OF THE CENTRAL FISSURE}

$a$. Diameter, from lower to upper extremity, $b$. Length measured by a thread foltaken by the sliding compass. lowing all the windings of the fissure.

Centesimal relation of $a$ to length of hemisphere.
Centesimal relation of $b$ to mesial length.

$$
\text { l. r. } \quad \text { l. } r \text { r. } \quad \text { l. } r . r \text { r. }
$$

$\begin{array}{lllllllll}\text { Kishu..... } & 9.0 & 8.6 & 50.0 & 48.0 & \text { II.7 } & \text { II.5 } & 43.0 & 42.3\end{array}$

$\begin{array}{lllllllll}\text { Nooktah.... } & 8.0 & 8.4 & 47.6 & 49.4 & \text { I0.7 } & \text { II.0 } & 42.6 & 42.5\end{array}$

Atana..... ( $7.3 \quad 7.7) \quad\left(\begin{array}{lllll}42.7 & 44.9\end{array}\right) \quad\left(\begin{array}{llll}10.8 & 10.6) & \left(\begin{array}{lll}42.2 & 42.7\end{array}\right)\end{array}\right.$

Avia....... (7.9 7.7 $) \quad\left(\begin{array}{lllll}51.6 & 50.3\end{array}\right) \quad\left(\begin{array}{lll}11.0 & 10.3\end{array}\right)\left(\begin{array}{lll}45.8 & 42.9\end{array}\right)$ 
Cunningham (p. 19I), taking the length of the fissure according to $b$ and comparing it with the mesial arc, obtained in whites:

In $5 \frac{1}{2}$ to $6 \frac{1}{2}$ mos. embryos............... 16.7

In full-term fotuses ................. 32.8

In 4 - to 5 -year-old children............. 33.9

In 16 adult females..................... 40.1

In 14 adult males...................... 38.6

and in the chimpanzee................ 5 I.I

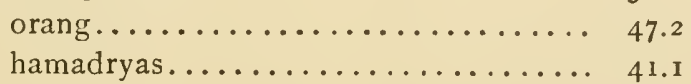

The length of the fissure, as seen from the above, is relatively greater in the Eskimo than in the whites; there is no decided sexual difference.

The straight length, or diameter, of the fissure can serve, in connection with the horizontal measures (from the vertical plane rising from the anterior extremity of the hemisphere to the two extremities of the fissure), in determining a Rolandic angle (by projection).

\section{LENGTH OF THE SYLVIAN}

Taking this length with a compass, from the exterior point of intersection of the Sylvian by the anterior or horizontal portion of the presylvian, to the angle which the ascending terminal branch forms with the main limb of the Sylvian, Eberstaller (quoting Cunningham) found it in whites as follows:

Up to $5.0 \mathrm{~cm}$., left in $22 \%$, right in $45 \%$ of hemispheres.

$5.1-6.0 \mathrm{~cm}$., left in $42 \%$, right in $44 \%$ of hemispheres.

$6.1-7.0 \mathrm{~cm}$., left in $27 \%$, right in I I \% of hemispheres.

Over $7.0 \mathrm{~cm}$., left in $9 \%$, right in $0.6 \%$ of hemispheres.

These figures show that the left Sylvian is more often the longer. Cunningham (p. 122) obtained similar results, but he measured the fissure from "the point at which its trunk appears on the outer surface of the hemisphere." As this point is almost generally less clearly defined than that employed by Eberstaller, 
I follow the latter authority. The Sylvians in the Eskimo measured as follows:

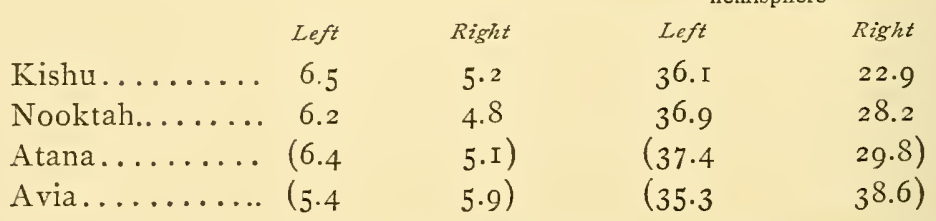

The left fissure is, in three of the Eskimo, both absolutely and relatively, decidedly longer than the right one.

Two additional useful and quite easy measures are, I think, the maximum breadth of the frontal lobes, measured by the sliding compass, with the branches applied over the most prominent points on the dorsum of the orbital parts of the inferior frontal gyri ; and a diameter between the extremities of the temporal and occipital lobes. These dimensions in the Eskimo are as follows :

BREADTH OF THE FRONTAL LOBES

Breadth

Kishu............. I I. $5 \mathrm{~cm}$.

Nooktah ............ $10.0 \mathrm{~cm}$.

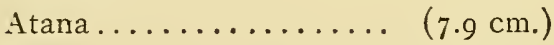

Avia................ (7.5 cm.)
Centesimal proportion to maximum width of the cerebrum

84.6

76.3

64.2

$64 \cdot 7$

These figures demonstrate well the superiority of the frontal lobes in Kishu's cerebrum, and the inferiority in this respect to both the males of both of the females.

TEMPORO-OCCIPITAL LOBES

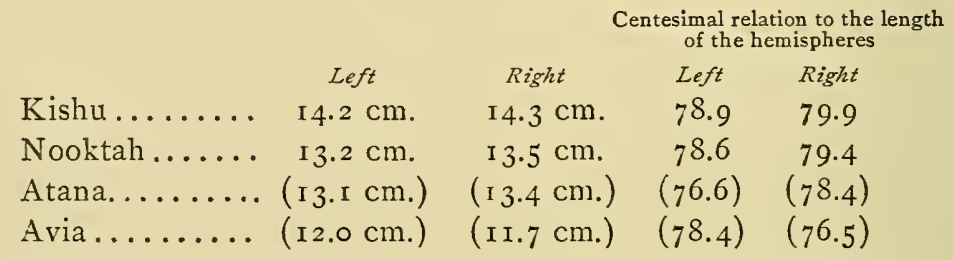


In this particular measurement the four brains show remarkable similarity.

\section{PREVIOUS RECORDS ON ESKIMO BRAINS}

The only previous records concerning Eskimo brains of which I could learn are those made by Chudzinski, published in the Bulletin de la Société d'Anthropologie de Paris, 1886.

The brains described by this author were those of Tobias Ignatius, male, 23 years; Paulus Abraham, male, 35 years; and Ulrika Hénocq, female, 24 years. The locality from which these subjects came is not stated, but there are reasons to believe that they belonged to the eastern Greenland Eskimo.

The three brains present some interesting similarities, but also many characteristics different from those of any of the specimens noted in this paper. In order to facilitate a comparison I shall introduce the principal part of Chudzinski's report.

The brains show " a considerable volume of the cerebral hemispheres"; "then one can see that the convolutions which constitute the external surface of the hemispheres_are large, simple, and very poor in secondary divisions, and that the sinuosities are but little flexuous." "That simplicity is especially marked over the frontal lobes"; "the same lobes are at the same time flattened infero-superiorly."

"The Sylvian fissure appears to be shorter than ordinarily, nearly horizontal, and of very simple contours," except in the woman, where it is little more complex, especially on the right. "Its anterior branch is generally very short and in the brain of P. A. altogether hidden by the temporal lobe."

"The Rolandic fissure is very long." "It is flexuous, especially in P. A. Ends on mesial surface" (in all ?).

"Occipital fissure very short externally. Calcarine fissure long and flexuous, especially in U. H."

"The frontal lobe is relatively short; the other lobes are, on the contrary, well developed, especially the parietal." 
"The first frontal gyrus is very large, especially in Tobias, but shows only a few incisures."

"The development of the second convolution is enormous, especially in P. A." "The gyrus is very simple in Tobias." "Among other features, there is a double anastomosis with the ascending frontal."

"The third frontal gyrus is very little developed; it is short and as ramassée sur elle même." "In Tobias it is reduced to a small, nearly smooth isle." Better developed in U. H.

"Ascending frontal gyrus very large." "Ascending parietal gyrus very flexuous in Paulus, very large in Tobias." The two gyri (asc. frontal and asc. parietal) are slender in U. H.

"The parietal convolutions generally simple and very extended," especially the second inferior.

"Occipital lobe generally simple, especially in Tobias."

Temporal lobe: "Extreme slenderness of first convolution"; "uncommon size of second convolution."

Internal (mesial) surface: "Enormous development in breadth of the mesial part of the first frontal convolution, especially in Tobias; a division of that convolution into two secondary gyri by an uninterrupted sulcus on the left hemisphere in Paulus." The secondary sulcus seems to be continuous with the subfrontal fissure. Similar sulcus on right in Paulus, but in several places interrupted by annectent gyri.

The convolution of the corpus callosum is generally very extended; but its breadth is very remarkable in Tobias, in its posterior part, and anteriorly in Ulrika, in whom it seems to divide itself along its middle into two secondary gyri."

The ovalaire lobule is enormous in Ulrika; on the other hand, the cuneiform is small, and in Ulrika it is reduced to a "pli de passage," hidden, in large part, in the calcarine and occipital fissures.

The similarities in the brains reported upon by Chudzinski and the one described here consist of the large volume of the 
cerebral hemispheres; long central fissures; sagittal division of the mesial parts of the superior frontal gyri ; the large size of the limbic lobe in Tobias, and the large size of the lobe with a tendency toward a longitudinal division in Ulrika.

The dissimilarities are: the poor differentiation in Chudzinski's specimens of the convolutions and the simple character of the sulci, especially over the frontal lobes; a defective development of the inferior frontal convolution (particularly in Tobias); very large ascending frontal and ascending parietal convolutions; simplicity of parietal convolutions; great slenderness of the superior temporal gyri; and very small cuneus.

The causes of the many dissimilarities are not clear. The morphological inferiority of the two male brains described by Chudzinski, and, on the other hand, the marked superiority of Kishu's and even of Nooktah's brain, may be to some extent individual conditions and represent more the extremes than the average of Eskimo brains. At the same time it is possible that Paulus Abraham and Tobias Ignatius belonged to some family of the great Eskimo tribe intellectually less developed than the Smith Sound group to which Kishu and Nooktah belonged. The Smith Sound party which Lieutenant Peary brought to New York were by no means dull or incapable people. This is especially well demonstrated in Menee, the son of Kishu, who has not only shown a remarkable facility for adjusting himself in every way to civilized life, but has made very good progress in the public school.

The marked differences of the specimens described by Chudzinski and in this paper from those of the whites, as well as among themselves, makes a future acquisition of Eskimo brains very desirable. 



\section{COLUMBIA UNIVERSITY LIBRARIES}

This book is due on the date indicated below, or at the expiration of a definite period after the date of borrowing, as provided by the rules of the Library or by special arrangement with the Librarian in charge.

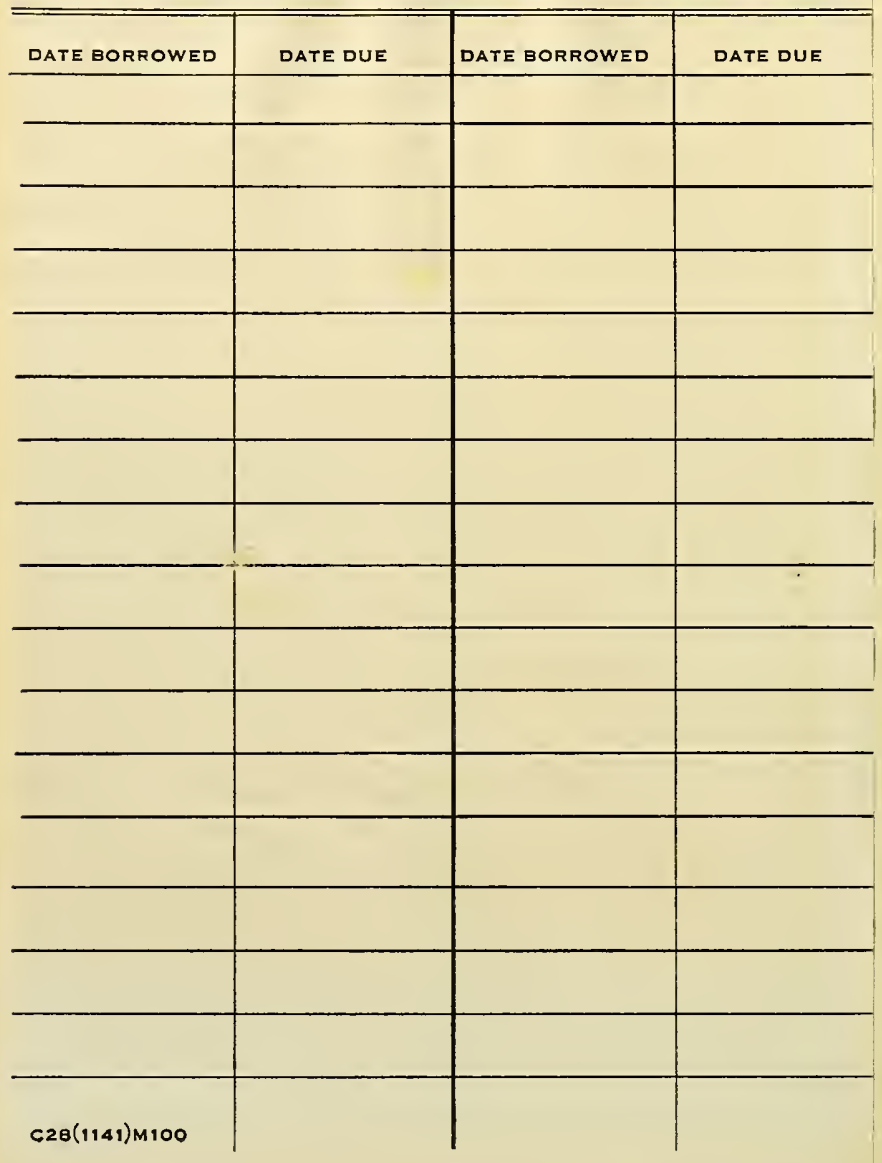




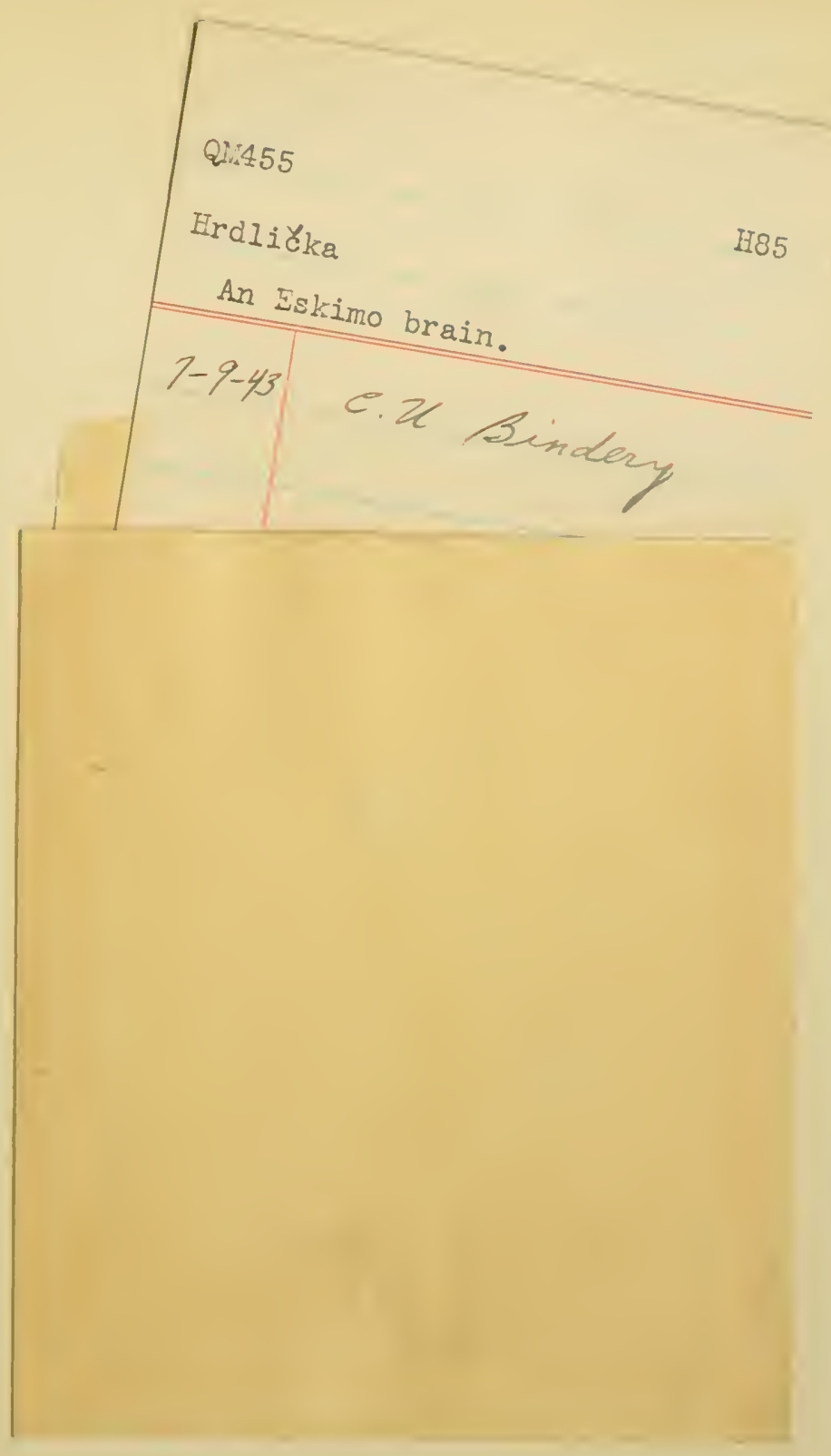




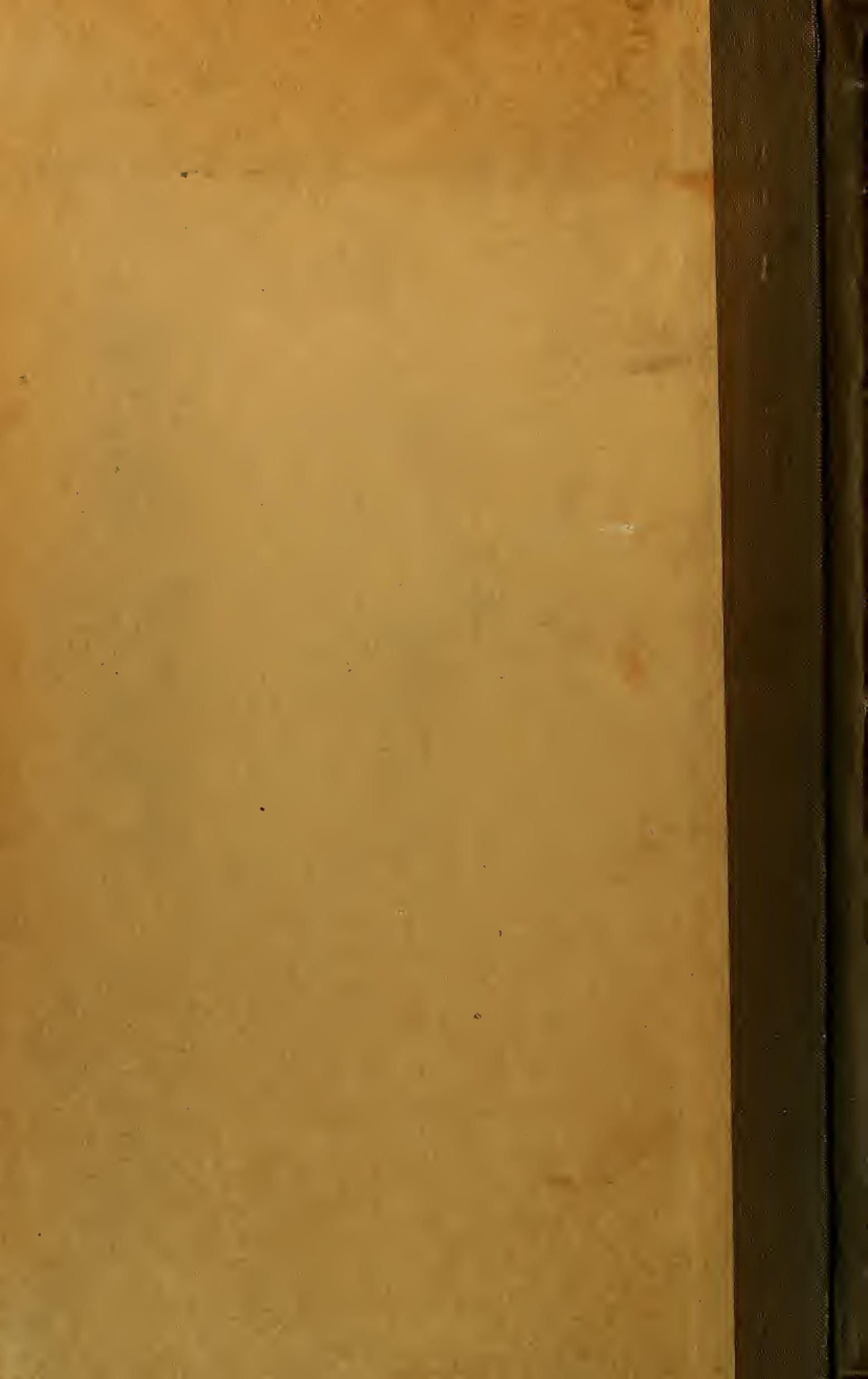

